\title{
Determining low permeability formation properties from absolute open flow potential
}

\author{
Fatemeh Belyadi \\ West Virginia University
}

Follow this and additional works at: https://researchrepository.wvu.edu/etd

\section{Recommended Citation}

Belyadi, Fatemeh, "Determining low permeability formation properties from absolute open flow potential" (2006). Graduate Theses, Dissertations, and Problem Reports. 1760.

https://researchrepository.wvu.edu/etd/1760

This Thesis is protected by copyright and/or related rights. It has been brought to you by the The Research Repository @ WVU with permission from the rights-holder(s). You are free to use this Thesis in any way that is permitted by the copyright and related rights legislation that applies to your use. For other uses you must obtain permission from the rights-holder(s) directly, unless additional rights are indicated by a Creative Commons license in the record and/ or on the work itself. This Thesis has been accepted for inclusion in WVU Graduate Theses, Dissertations, and Problem Reports collection by an authorized administrator of The Research Repository @ WVU. For more information, please contact researchrepository@mail.wvu.edu. 
Deter mining L ow Permeability F ormation Properties from A bsolute

Open Flow Potential

Fatemeh Belyadi

Thesis submitted to the

C ollege of E ngineering and Mineral Resources

at West Virginia University

in Partial Fulfillment of the Requirements

for the Degree of

\author{
M aster of Science \\ In \\ Petroleum and Natural $\mathrm{G}$ as E ngineering \\ K hashayar A minian, Chair \\ Samuel A meri, M.S. \\ Shahab M ohaghegh, Ph.D.
}

Department of Petroleum and Natural G as E ngineering

M organtown, W est Virginia

2006

K eywords: AOF P, Skin factor, Permeability 


\title{
ABSTRACT
}

\section{DETERMINING LOW PERMEABILITY FORMATION PROPERTIES FROM ABSOLUTE OPEN FLOW POTENTIAL \\ Fatemeh Belyadi}

\begin{abstract}
Absolute Open Flow Potential (AOFP) is often the only productivity information available from low permeability gas formations particularly in the Appalachian Basin. Absolute Open Flow Potential (AOFP) is commonly evaluated through a single point test due to its cost effectiveness. In low permeability reservoirs, the time required for obtaining stabilized flow rate is often very long. Therefore, stabilized AOFP may not be achieved in short tests. Furthermore, most low permeability gas wells are hydraulically fractured to improve their productivity. Therefore, the post-fracture measured AOFP could be significantly influenced by fracture properties.
\end{abstract}

The objective of this was to develop a methodology to estimate formation properties from AOFP. Conventional methods for pressure transient analysis or deliverability testing analysis cannot be used since they require multiple pressure and rate data. To achieve the objective, the impact of formation properties on AOFP was studied. Several different solutions were considered to determine the relationship among AOFP, permeability, and skin factor. They included pseudo-steady state radial flow, transient radial flow, and bilinear flow. The non-Darcy flow effects were also included in all these cases. The results of this study are summarized by a series of correlations for estimation of formation properties particularly the permeability from the AOFP. 


\section{ACKNOWLEDGEMENTS}

The writing of a thesis can be a lonely and isolating experience, yet it is obviously not possible without the personal and practical support of numerous people. My sincere gratitude goes to my parents, my brothers and sister, and all my friends for their love, support, and patience over the last few years. My father taught me, among other things, that with a good education, hard work, and perseverance, one can reach great heights in life. My mother is also a source of inspiration for me.

I wish to thank Dr. Kashy Aminian, my research advisor, for his valuable support and guidance, and for having been a constant source of inspiration for this work. I really admire Dr. Aminian's dedication to his research; I have learned a lot from his approach of conducting research. I am thankful to Dr. Sam Ameri, Chair of the Petroleum \& Natural Gas Engineering Department who has been a role model for me during my studies at West Virginia University. I am thankful to Dr. Shahab Mohaghegh for his encouragement throughout my studies at WVU and for his participation in the examining committee. I would also like to thank the other faculty of the Petroleum \& Natural Gas Engineering Department for their guidance and assistance during my graduate program at West Virginia University. 


\section{DEDICATION}

I thank God for giving me the opportunity to finish this segment of my education. This work is dedicated to my extraordinary parents. I thank them for being supportive, patient, and my best friend. I also dedicate my work to my brother who passed away 10 years ago. Ali, I love you, and I am saddened that you are not here today. 


\section{TABLE OF CONTENTS}

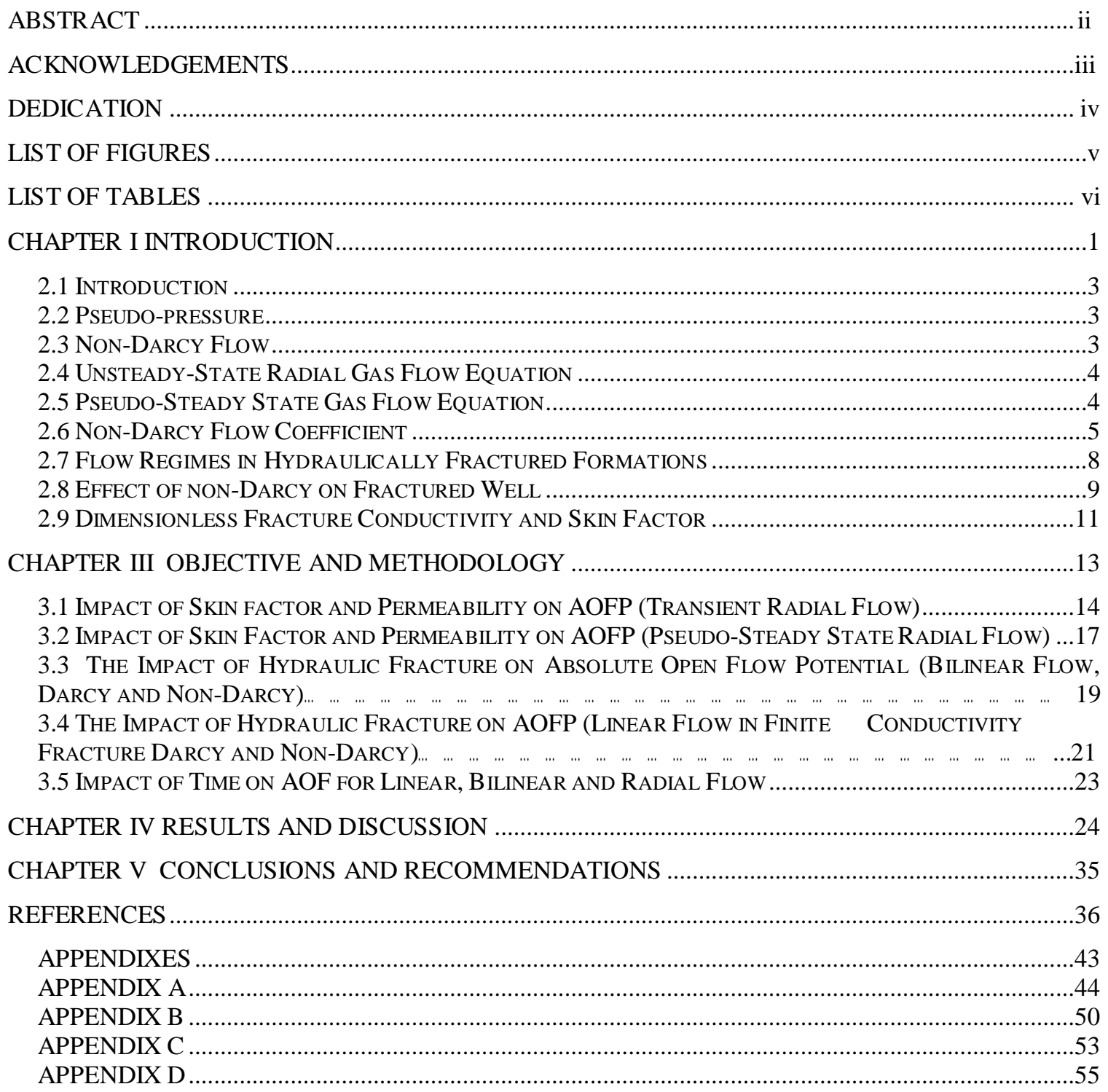

\section{LIST OF FIGURES}

Figure 2.2: Skin factor as a function of fracture length and conductivity (Cinco-Ley, Heber, and Samaniego, 1981)

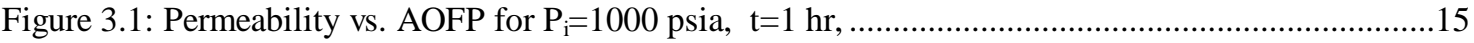

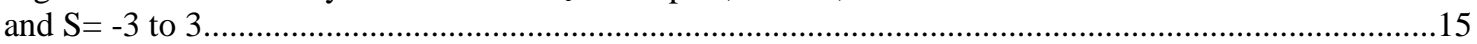

Figure 3.2: Permeability vs. AOFP for $\mathrm{P}_{\mathrm{i}}=1000,1500$, and 2000 psia ................................................16

Figure 3.3: Skin Factor vs. AOFP for Various Permeability Values at $P_{R}=1500$ psia..........................18

Figure 3.4: AOFP vs. Permeability for zero skin factor, $P_{R}=1000,1500$, and 2000 psia..........................19

Figure 4.1: Permeability vs. AOFP for $\left(\mathrm{P}_{\mathrm{i}}=1500 \mathrm{psi}, \mathrm{t}=1 \mathrm{hr}\right.$, and $\mathrm{S}=-3$ to 3$)$.....................................24

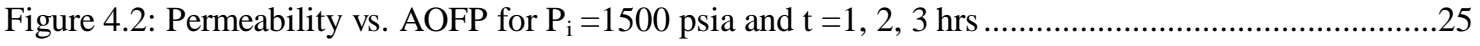




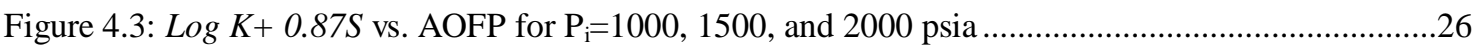

Figure 4.4: $\log K+0.87 S$ vs. AOFP for (different $\beta$ correlation) ………..............................................2

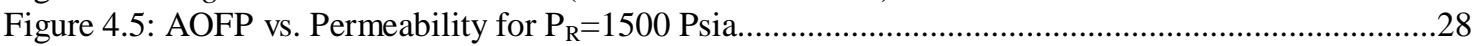

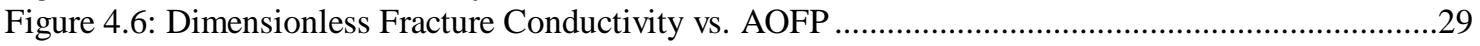

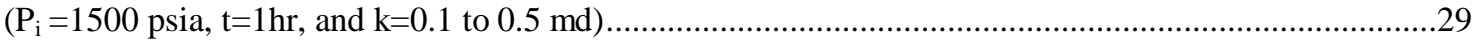

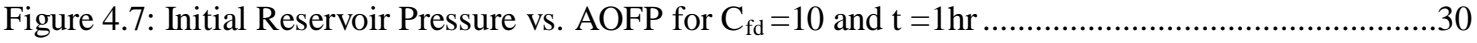

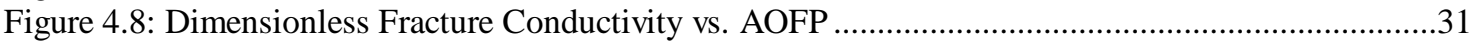

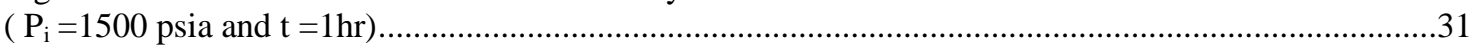

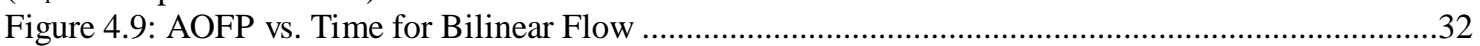

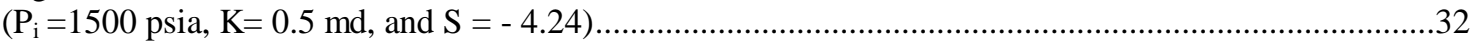

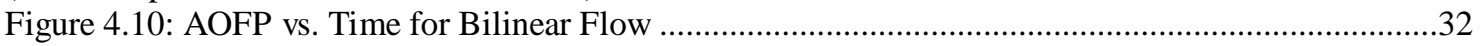

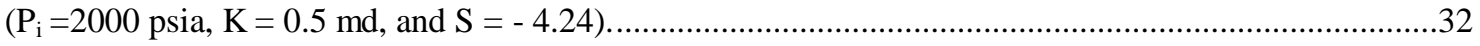

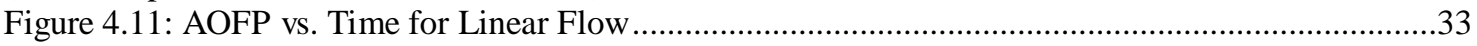

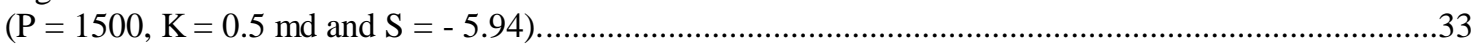

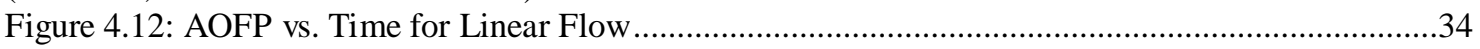

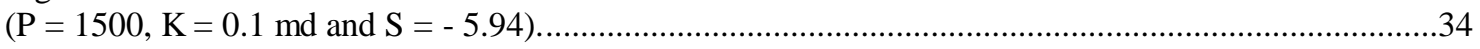

Figure A.1: Illustrates the nonlinearity of pseudo-pressure as a function of pressure.............................49

Figure A.2: $\mathrm{Z}$ factor, viscosity, and compressibility calculation program (Aminian, 2000) ......................49

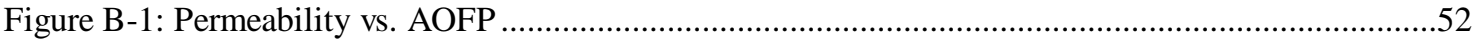

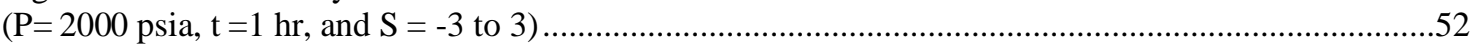

\section{LIST OF TABLES}

Table A-1: Z factor, viscosity, compressibility results

Table A-2: Pseudo-pressure calculation using the $\mathrm{z}$ factor, viscosity, compressibility values from stimulator.

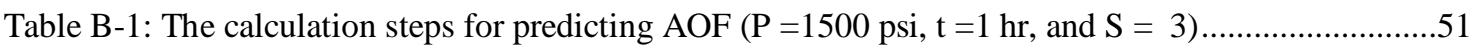

Table B-2: The calculation steps for predicting AOFP, using different $\beta$ correlation (Janecicek, Katz) ...51

Table C-1: Steps for estimation AOFP using pseudo-steady state equation ............................................53

Table D-1: AOFP calculation using bilinear non-Darcy flow regime $(\mathrm{p}=1500 \mathrm{psia}$ and $\mathrm{K}=0.5)$ ).............60

Table D-2: AOFP calculation using linear non-Darcy flow regime ( $\mathrm{p}=1500 \mathrm{psia}$ and $\mathrm{K}=0.5) \ldots \ldots \ldots \ldots \ldots \ldots . . .60$

Table D-3: Converting $\mathrm{C}_{\mathrm{fd}}$ values to skin factor and AOFP calculation using bilinear non-Darcy flow regime, $(\mathrm{p}=1500 \mathrm{psia} \text { and } \mathrm{K}=0.5, \mathrm{t}=1 \mathrm{hr})^{*}$.

Table D-4: Converting $\mathrm{C}_{\mathrm{fd}}$ values to skin factor and AOFP calculation using bilinear Darcy flow regime $(\mathrm{p}=1500 \mathrm{psia} \text { and } \mathrm{K}=0.5, \mathrm{t}=1 \mathrm{hr})^{*}$...

Table D-5: AOF calculation using pressure transient equation for radial flow regime, $(\mathrm{p}=1500 \mathrm{psia}$ and $\mathrm{K}=0.5)^{*}$ 


\section{Nomenclature:}

q Flow rate $(\mathrm{MSCF} / \mathrm{D})$

$\mathrm{S}=$ Skin factor

$S^{`}=$ Apparent skin factor

$\mathrm{k}=$ permeability $(\mathrm{md})$

$\mathrm{t}=$ Time $(\mathrm{Hrs})$

$=$ Porosity $(\%)$

$\mathrm{i}=$ Initial gas Viscosity $(\mathrm{cp})$

$\mathrm{C}_{\mathrm{ti}}=$ Initial Compressibility $\left(\mathrm{psia}^{-1}\right)$

$\mathrm{m}\left(\overline{\mathrm{p}}_{\mathrm{R}}\right)=$ Reservoir pseudo-pressure $\left(\mathrm{psia}^{2} / \mathrm{cp}\right)$

$\mathrm{m}\left(\mathrm{P}_{\mathrm{i}}\right)=$ Initial Reservoir pseudo-pressure $\left(\mathrm{psia}^{2} / \mathrm{cp}\right)$

$\mathrm{r}_{\mathrm{w}}=$ Wellbore radius $(\mathrm{ft})$

$h=$ Net pay thickness $(\mathrm{ft})$

$C_{D}=$ dimensionless wellbore storage coefficient

$\mathrm{C}_{\mathrm{r}}=$ Fracture Conductivity $(\mathrm{md}-\mathrm{ft})$

$C_{f D}=$ dimensionless fracture conductivity

$\mathrm{C}_{\mathrm{t}}=$ total compressibility $\left(\mathrm{psi}^{-1}\right)$

$=$ velocity $(\mathrm{ft} / \mathrm{hr})$

$\mathrm{h}=$ formation thickness $(\mathrm{ft})$

$\mathrm{k}=$ permeability $(\mathrm{md})$

$\mathrm{M}=$ molecular weight of the gas (lbm/lbmole)

$p=$ pressure $(p s i)$ 


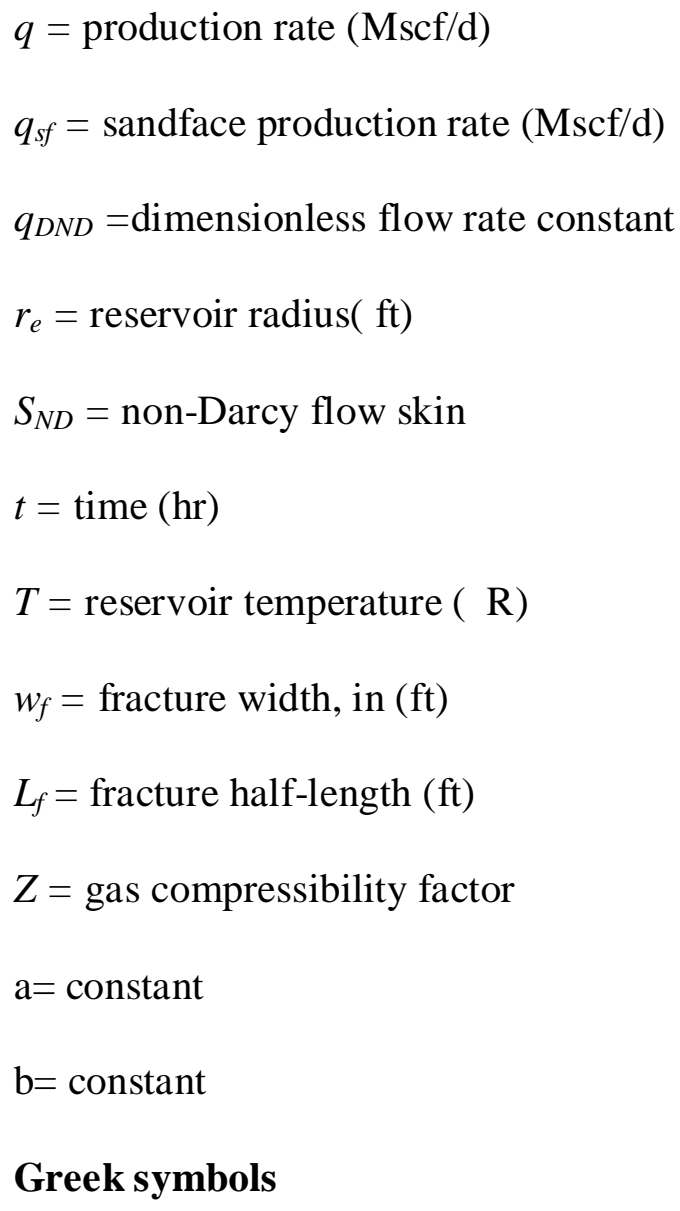

\section{Subscripts and superscripts}

$D=$ dimensionless

$f=$ fracture

$\mathrm{i}=$ initial

$\mathrm{w}=$ wellbore

$\mathrm{W}_{\mathrm{f}}=$ flowing wellbore 


\section{CHAPTER I \\ INTRODUCTION}

The absolute open flow potential (AOFP) represent the maximum flow rate that a well could sustain against atmospheric backpressure. Different definitions of stabilized AOFP of a gas well can be found in the literature. The definition of AOFP is often confused; it does add confusion to a discussion about stabilized AOFP determination. Since a natural gas well will not exhibit a flowing sandface pressure of less than atmospheric pressure for normal production operations, we shall use the definition of stabilized AOFP as the theoretical stabilized rate at which the well would produce at a stabilized flowing sandface backpressure of atmospheric pressure. While this definition of stabilized AOFP has the limitation of variable atmospheric pressure values, the limitation is negligible since in most areas, the standard atmospheric pressure is regarded to be about $14.7 \mathrm{psia}$ (Lee et al 1982).

The stabilized deliverability equation can be used to predict the AOFP of a gas well. To develop the stabilized deliverability equation; four-point tests such as flow-after-flow, isochronal, and modified isochronal tests are usually conducted (Rawlins et al 1936). Four-point tests generally are not used in the Appalachian Basin due to long stabilization time in low permeability formations. Most of the operators however utilize single point test to determine AOFP of a gas well. 
It is desirable to develop a methodology for estimating formation properties from AOFP since it is often the only productivity information available from low permeability gas formations particularly in the Appalachian Basin. In low permeability reservoirs, the time required for obtaining stabilized flow rate is often very long. Therefore, stabilized AOFP may not be achieved in short tests. Furthermore, most low permeability gas wells are hydraulically fractured to improve their productivity. Therefore, the post-fracture measured AOFP could be significantly influenced by fracture properties. 


\section{CHAPTER II}

\section{LITERATURE REVIE W}

\subsection{Introduction}

There are a number of available solutions to general partial differential equation that describe the gas flow through porous media. Two aspect of gas must be included in the solutions for gas flow through porous media. They are the dependency of gas properties, i.e. viscosity and density, on the pressure and additional pressure drop caused by high gas velocity (non-Darcy flow effects).

\subsection{Pseudo-pressure}

The pressure dependency of gas properties is accounted by introducing pseudo-pressure. Al-Hussainy and Ramey (1966) presented pseudo-pressure as follows:

$$
\mathrm{m}(\mathrm{p})=\frac{2 \mathrm{p}}{\mu \mathrm{z}} \mathrm{dp}
$$

\subsection{Non-Darcy Flow}

Darcy's (1956) law describes the flow of fluid in a porous medium at low velocities. Darcy's law is mathematically described by the following equation:

$$
\frac{\Delta \mathrm{p}}{\Delta \mathrm{L}}=\frac{\mu \nu}{\mathrm{K}}
$$

Forchheimer (1901) added the second term to Darcy's law equation by discovering that pressure gradient required to maintain a certain flow rate through porous media was higher than that predicted by Darcy's law:

$$
\frac{\Delta \mathrm{p}}{\Delta \mathrm{L}}=\frac{\mu v}{\mathrm{~K}}+\beta \rho v^{2}
$$




\subsection{Unsteady-State Radial G as F low E quation}

Unsteady state constant rate solution, which is usually used for drawdown analysis, is defined as follows (Houpeurt, 1959):

$$
\mathrm{m}\left(\mathrm{p}_{\mathrm{i}}\right)-\mathrm{m}\left(\mathrm{p}_{\mathrm{wf}}\right)=\frac{1637 \mathrm{qT}}{\mathrm{kh}}\left[\operatorname{logt}+\log \frac{\mathrm{k}}{\varphi \mu_{\mathrm{i}} \mathrm{c}_{\mathrm{t}_{\mathrm{i}}} \mathrm{r}_{\mathrm{w}}^{2}}-3.23+0.869 \mathrm{~S}^{\prime}\right]
$$

Muskut (1969), Katz (1959), and Wattenbarger and Ramy (1968) all describe non-Darcy flow close to the wellbore as a rate dependent skin:

$$
\mathrm{S}^{\prime}=\mathrm{S}+\mathrm{Dq}
$$

As Equation 5 indicates, the rate dependent or total skin factor $\left(\mathrm{S}^{\prime}\right)$ consist of a constant component $(\mathrm{S})$, and a rate dependent part $(\mathrm{Dq})$. Skin factor $(\mathrm{S})$ represents formation alteration (damage or stimulation), whereas rate dependent part represents non-Darcy flow pressure drop. The flow rate coefficient (D) is defined by following equation (Katz et al 1959):

$$
\mathrm{D}=\frac{2.22 * 10^{-15} \gamma_{\mathrm{g}} \mathrm{k}}{\overline{\mu h r_{\mathrm{w}}}} \beta
$$

\subsection{Pseudo-Steady State G as F low E quation}

Pseudo-steady state constant rate solution, which is usually used for the deliverability test analysis, is defined as follows (Houpeurt, 1959):

$$
\mathrm{m}\left(\overline{\mathrm{P}_{\mathrm{R}}}\right)-\mathrm{m}\left(\mathrm{P}_{\mathrm{wf}}\right)=\frac{1422 \mathrm{Tq}_{\mathrm{sc}}}{\mathrm{kh}}\left[\ln \left(\frac{0.472 \mathrm{r}_{\mathrm{e}}}{\mathrm{r}_{\mathrm{w}}}\right)+\mathrm{S}+\mathrm{Dq}_{\mathrm{sc}}\right]
$$




\subsection{Non-Darcy Flow C oefficient}

The critical factor for evaluating the non-Darcy effect is to obtain an estimate of nonDarcy coefficient, $\beta$. Janicek and Katz (1955) were the first to develop a correlation for non-Darcy coefficient using sandstone, limestone, and dolomite cores in their laboratory experiment. They proposed non-Darcy coefficient for natural porous media which was defined as following:

$$
\beta=1.82 \times 10^{8} \mathrm{k}^{-5 / 4} \varphi^{-3 / 4}
$$

Where:

$\mathrm{k}=$ Permeability $(\mathrm{md})$

$\beta=$ non-Darcy coefficient $(1 / \mathrm{cm})$

They found that there was no difference among the non-Darcy coefficient for various rock types. Tek et al. (1962) developed a correlation for non-Darcy coefficient, by analyzing Janicek and Katz data. There correlation is as follows:

$$
\beta=\frac{2.33 \times 10^{10}}{\mathrm{k}^{1.2}}
$$

Where:

$\mathrm{k}=$ Permeability (md)

$\beta=$ non-Darcy coefficient $(1 / \mathrm{ft})$

Cooke (1973) studied non-Darcy coefficient for several fluids in propped fracture at various temperatures and introduced the following equation:

$$
\beta=\mathrm{bk}^{-\mathrm{a}}
$$


Where $\mathrm{k}$ is fracture permeability (md), $\beta$ is measured in $\mathrm{ft}^{-1}$, a and $\mathrm{b}$ are depend on proppant type. Table 2.1, summarizes the constant values for Cooke’s equation.

\section{Table 2.1: Constant a' and b' in Cook's equation}

\begin{tabular}{|c|c|c|}
\hline $\begin{array}{c}\text { sand size } \\
\text { (mesh) }\end{array}$ & a' & b' \\
\hline 8 to 12 & 1.24 & 17423.61 \\
\hline 10 to 20 & 1.34 & 27539.48 \\
\hline 20 to 40 & 1.54 & 1104070.39 \\
\hline 40 to 60 & 1.6 & 69405.31 \\
\hline
\end{tabular}

Geertsma (1974) analyzed the data obtained from unconsolidated sandstones, consolidated sandstones, limestones, and dolomites from his experiments, and defined the following equation:

$$
\beta=\frac{0.005}{\mathrm{k}^{0.5} \varphi^{5.5}}
$$

Where:

$\mathrm{K}=$ Permeability $\left(\mathrm{cm}^{2}\right)$

$\beta=$ Non-Darcy coefficient $(1 / \mathrm{cm})$

Pascal et al. (1980) proposed a mathematical model to estimate the fracture length and the non-Darcy coefficient, using variable rate tests for low permeability hydraulically fractured wells. Based on their analysis, the following correlation for non-Darcy coefficient was defined:

$$
\beta=\frac{4.8 \times 10^{12}}{\mathrm{k}^{1.176}}
$$

Where: 
$\mathrm{k}=$ Permeability $(\mathrm{md})$

$\beta=$ Non-Darcy coefficient $(1 / \mathrm{cm})$

Jones (1987) carried out his experiment on 355 sandstone and 29 limestone cores, with different core types such as fine grain sandstone, vuggy limestone, and crystalline limestone. Based on his analysis the following correlation for non-Darcy coefficient was developed:

$$
\beta=\frac{6.15 \times 10^{10}}{\mathrm{k}^{1.55}}
$$

Where:

$\mathrm{k}=$ Permeability (md)

$\beta=$ Non-Darcy coefficient $(1 / \mathrm{ft})$

Li et al. (1995) studied the effect of non-Darcy using a reservoir simulator. They also conducted a series of experiments by injecting the Nitrogen at different flow rates, in several different directions in to a wafer-shaped Berea sandstone core. Then, the pressure drops from simulations and experiments were compared and the following correlation for non-Darcy coefficient was obtained:

Where:

$$
\beta=\frac{11500}{k \varphi}
$$

$\mathrm{k}=$ Permeability $(\mathrm{d})$

$\beta=$ Non-Darcy coefficient $(1 / \mathrm{cm})$

Coles and Hartman (1998) proposed a correlation for non-Darcy coefficient by conducting their experiment on limestone and sandstone samples,

$$
\beta=\frac{1.07 \times 10^{12} \times \varphi^{0.449}}{\mathrm{k}^{1.88}}
$$

Where: 
$\mathrm{k}=$ Permeability $(\mathrm{md})$

$\beta=$ non-Darcy coefficient $(1 / \mathrm{ft})$

According to Thauvin and Monhaty's (1998) analysis, the comparison of Erugun's flow equation with Forchheimer equation leads to following equation:

$$
\beta=\mathrm{ab}^{-1 / 2}\left(10^{-8} \mathrm{k}\right)^{-1 / 2} \varphi^{-3 / 2}
$$

Where:

$\mathrm{a}=1.75$

$b=150$

$\mathrm{k}=$ Permeability $(\mathrm{d})$

$\beta=$ Non-Darcy coefficient $(1 / \mathrm{cm})$

\subsection{Flow R egimes in H ydraulically Fractured Formations}

Presence of a hydraulic fracture will alter the pressure response of the well since the flow geometry in the fracture is linear. In well test analysis three types of fracture behaviors are usually observed (Gringarten et al 1974)

(a) Finite conductivity fractures (low conductivity)

(b) Infinite conductivity fractures (high conductivity)

(c) Uniform flux fractures.

Cinco, Samaniego and Dominguez (1978) and Cinco and Samaniego (1981) considered the finite conductivity fractures. In the finite conductivity fractures, different flow regimes are observed at different time. At early times, two linear flows occur one in the fracture and one in the formation as illustrated in Figure 2.1. These two simultaneous linear flows give rise to the bilinear flow period. This flow regime is recognized as a 
straight line with the slope of $1 / 4$ in both pressure and the pressure derivative against time on a log-log paper (diagnostic plot). Following the bilinear flow period, linear flow period will take place. This flow regime is recognized as a straight line with the slope of $1 / 2$ on the diagnostic plot. Upon conclusion of the linear flow regime, a transitional flow regime will initiates and eventually, radial flow will take place (See Figure $2.1 \mathrm{c}$ ).

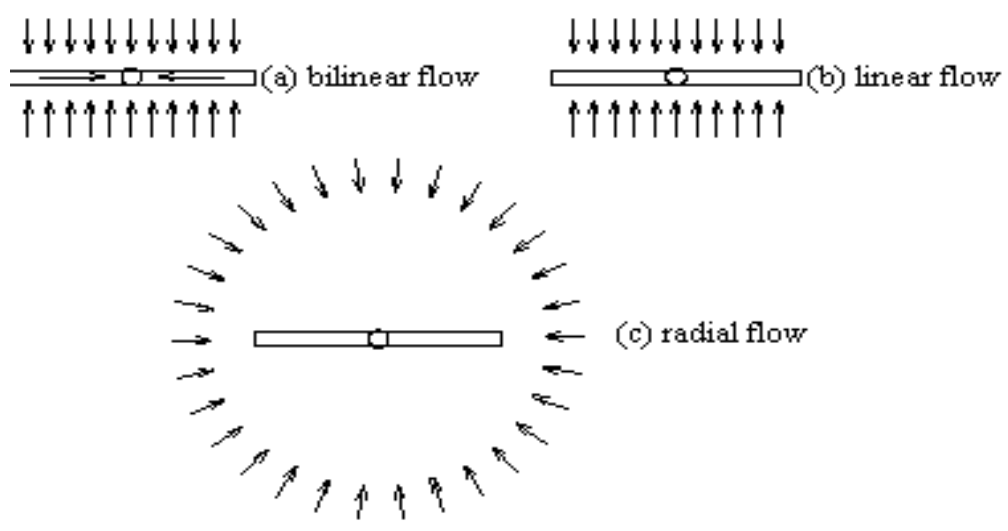

Figure 2.1: Different flow regimes for finite conductivity fracture (C inco et al, 1978)

\subsection{Effect of non-D arcy on Fractured Well}

The effect of the non-Darcy flow on hydraulically fractured well has been discussed in several papers. Millheim and Cichowicz (1968) were first to observe the effect of nonDarcy flow on vertically fractured well. Holditch and Morse (1976) discussed the effect of the non-Darcy flow in both reservoir and fracture system by using numerical models. They concluded that non-Darcy flow in the fracture system reduced the apparent fracture conductivity. Guppy et al. (1982) developed a semi-analytical model for non-Darcy flow in wells with finite conductivity fractures. This model was able to account for the fracture and reservoir interaction under non-Darcy flow conditions in the fracture. They presented 
the changes in flux distribution in the fracture under non-Darcy flow and concluded reduction in apparent conductivity of the fracture.

Cinco and Sameniego (1977) have shown that during the bilinear flow the dimen sionless pseudo-pressure responses of finite-conductivity fracture under Darcy flow condition may be expressed by following form:

$$
\mathrm{m}_{\mathrm{wD}}(\text { Darcy })=\frac{\pi}{\Gamma(5 / 4) \sqrt{2 \mathrm{C}_{\mathrm{fD}}}} \mathrm{t}_{\mathrm{D}}^{1 / 4}
$$

Guppy et al. (1982) have shown that during the bilinear flow the dimensionless pseudopressure responses of finite-conductivity fracture under non-Darcy flow condition may be expressed by following form:

$$
\mathrm{m}_{\mathrm{wD}}(\text { non }- \text { Darcy })=\frac{\pi}{\Gamma(5 / 4) \sqrt{2 \mathrm{C}_{\mathrm{fD}, \mathrm{app}}}} \mathrm{t}_{\mathrm{D}}^{1 / 4}
$$

According to Camacho (1984), during the linear flow the dimensionless pseudo-pressure responses of finite-conductivity fractures under Darcy and non-Darcy flow can be defined respectively by following equations:

$$
\begin{gathered}
\mathrm{m}_{\mathrm{wD}}(\text { Darcy })=\sqrt{\pi \mathrm{t}_{\mathrm{D}}}+\frac{\mathrm{a}}{\mathrm{C}_{\mathrm{fD}}} \\
\mathrm{m}_{\mathrm{wD}}\left(\text { non - Darcy) }=\sqrt{\pi \mathrm{t}_{\mathrm{D}}}+\frac{\mathrm{a}}{\mathrm{C}_{\mathrm{fD}, \mathrm{app}}}\right.
\end{gathered}
$$

Where:

$\mathrm{a}=\pi / 3$ for $\mathrm{C}_{\mathrm{fD}} \quad 25$ 


$$
\begin{aligned}
& a=0.944 \text { for } C_{f D} \quad 10 \\
& a=0.902 \text { for } C_{f D} \quad 5
\end{aligned}
$$

Dimensionless pseudo-pressure and dimensionless time are defined as following (Guppy et al 1982):

$$
\begin{aligned}
\mathrm{m}_{\mathrm{D}}\left(\mathrm{t}_{\mathrm{D}}\right) & =\frac{\mathrm{kh}}{1,422 \mathrm{qT}}\left[\mathrm{m}\left(\mathrm{p}_{\mathrm{i}}\right)-\mathrm{m}\left(\mathrm{p}_{\mathrm{wf}}\right)\right] \\
\mathrm{t}_{\mathrm{D}} & =\frac{2.637 * 10^{-4} \mathrm{k}}{\varphi\left(\mu \mathrm{C}_{\mathrm{t}}\right)_{\mathrm{i}} \mathrm{x}_{\mathrm{f}}^{2}} \mathrm{t}
\end{aligned}
$$

Transient pressure responses of finite conductivity fractures with Non-Darcy flow are governed by dimensionless fracture conductivity and dimensionless flow rate (Guppy et al 1982):

$$
\begin{gathered}
C_{f D} \frac{k_{f} w_{f}}{k x_{f}} \\
q_{D N D} \frac{4.64 * 10^{16} k_{f} M q}{w_{f} h_{i}}
\end{gathered}
$$

To take the non-Darcy flow in to the consideration the apparent fracture conductivity $\left(C_{f D, a p p}\right)$ is defined by following equation (Guppy et al 1982):

$$
\mathrm{C}_{\mathrm{fD}, \text { app }}=\frac{\mathrm{C}_{\mathrm{fD}}}{\left(1+0.31 \mathrm{q}_{\mathrm{DND}}\right)}
$$

\subsection{Dimensionless Fracture Conductivity and Skin F actor}

Cinco-Ley, Heber, and Samaniego (1981), defined skin factor as a function of dimensionless fracture conductivity and fracture half length. For bilinear flow regime (in 
finite conductivity fracture $)\left(c_{f d}<100\right), \frac{r_{w} e^{s}}{x_{f}} \quad 0.5$, skin factor can be calculated from estimation of $\frac{r_{w} e^{s}}{x_{f}}$ value from the figure 2.2 for each value of dimensionless fracture conductivity.

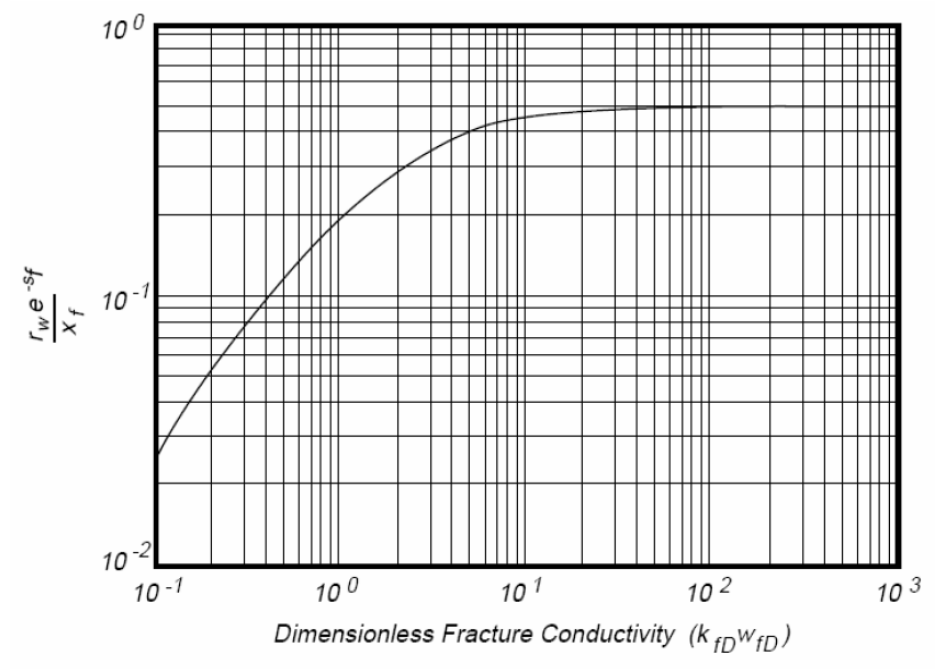

Figure 2.2: Skin factor as a function of fracture length and conductivity (C inco-L ey, Heber, and Samaniego, 1981) 


\section{CHAPTER III}

\section{OBJECTIVE AND METHODOLOGY}

The goal of this study was to develop a correlation between permeability, skin factor and AOFP in low permeability formation. To achieve the objective, a methodology consisting of the following 5 steps was employed:

1. The impact of skin factor and permeability on absolute open flow potential was evaluated using unsteady state transient radial flow solution.

2. The impact of skin factor and permeability on absolute open flow potential was evaluated using pseudo-steady state radial flow solution.

3. The impact of hydraulic fracture on absolute open flow potential was evaluated using bilinear flow solution (Darcy and non-Darcy).

4. The impact of hydraulic fracture on absolute open flow potential was evaluated using linear flow solution (Darcy and non-Darcy).

5. The impact of test duration (time) on absolute open flow potential was evaluated using linear, bilinear and radial flow solutions.

Table 3.1 and 3.2 shows the parameters and ranges that were used through out this study.

Table 3.1: Parameters used, throughout this study

\begin{tabular}{|c|c|}
\hline Formation porosity $(\%)$ & 0.2 \\
\hline Gas Density $\left(\mathrm{lbm} / \mathrm{ft}^{3}\right)$ & 13.84 \\
\hline $\mathrm{k}_{\mathrm{f}}(\mathrm{md})$ & 50000 \\
\hline $\mathrm{w}_{\mathrm{f}}(\mathrm{ft})$ & $1.00 \mathrm{E}-02$ \\
\hline $\mathrm{x}_{\mathrm{f}}(\mathrm{ft})$ & $5.00 \mathrm{E}+02$ \\
\hline $\mathrm{T}\left({ }^{\circ} \mathrm{R}\right)$ & $5.40 \mathrm{E}+02$ \\
\hline $\mathrm{r}_{\mathrm{w}}(\mathrm{ft})$ & $3.30 \mathrm{E}-01$ \\
\hline$\beta\left(\mathrm{ft}^{-1}\right)$ & $1.79 \mathrm{E}+05$ \\
\hline
\end{tabular}


Table 3.2: $R$ anges used, throughout this study

\begin{tabular}{|c|c|}
\hline Parameter & Range \\
\hline Pressure (psia) & 1000,1500 and 2000 \\
\hline Permeability & 0.1 to 1 \\
\hline Skin Factor & -3 to 3 \\
\hline Dimensionless fracture conductivity & 10 to 100 \\
\hline
\end{tabular}

\subsection{Impact of Skin factor and Per meability on AOF P (Transient R adial Flow)}

The first step of this study was to evaluate the impact of permeability and skin factor on absolute open flow potential using unsteady state transient radial flow equation. Gas viscosity and $\mathrm{z}$ factor were calculated at the initial reservoir pressure of 1000, 1500, and 2000 psia respectively. In addition, pseudo-pressure was calculated by numerical integration using equation 1 (Refer to Figure A.1 and A.2 in the Appendix for interface of simulation program and relation between pressure and pseudo-pressure respectively). AOFP value was calculated using unsteady state transient radial flow solution. Furthermore, unsteady state transient radial flow equation was divided into three parts as follows:

$$
\begin{gathered}
\mathrm{a}=\frac{1637 \mathrm{~T}}{\mathrm{kh}}[0.869 \mathrm{D}]=\frac{1422 \mathrm{TD}}{\mathrm{kh}} \\
\mathrm{b}=\frac{1637 \mathrm{~T}}{\mathrm{kh}}\left[\log \mathrm{t}+\log \frac{\mathrm{k}}{\varphi \mu_{\mathrm{i}} \mathrm{c}_{\mathrm{ti}} \mathrm{r}_{\mathrm{w}}^{2}}-3.23+0.869 \mathrm{~S}\right] \\
\mathrm{c}=\mathrm{m}\left(\mathrm{p}_{\mathrm{i}}\right)-\mathrm{m}\left(\mathrm{p}_{\mathrm{wf}}\right)
\end{gathered}
$$

To calculate AOFP, quadratic formula in the excel program was used.

$$
\mathrm{AOFP}=\frac{-\mathrm{b} \sqrt{\mathrm{b}^{2}-4 a c}}{2 \mathrm{a}}
$$


In order to develop a correlation between permeability, skin factor and AOFP the following steps were considered:

AOFP values were calculated for permeability data range from 0.1 to $1 \mathrm{md}$, keeping skin factor, initial reservoir pressure and time constant, then skin factor values were varied from -3 to 3 (Refer to Table B.1 in the Appendix B for tabulated result).

The permeability was plotted against AOFP for various skin factors at specified initial reservoir pressure and test duration as illustrated in Figure 3.1.

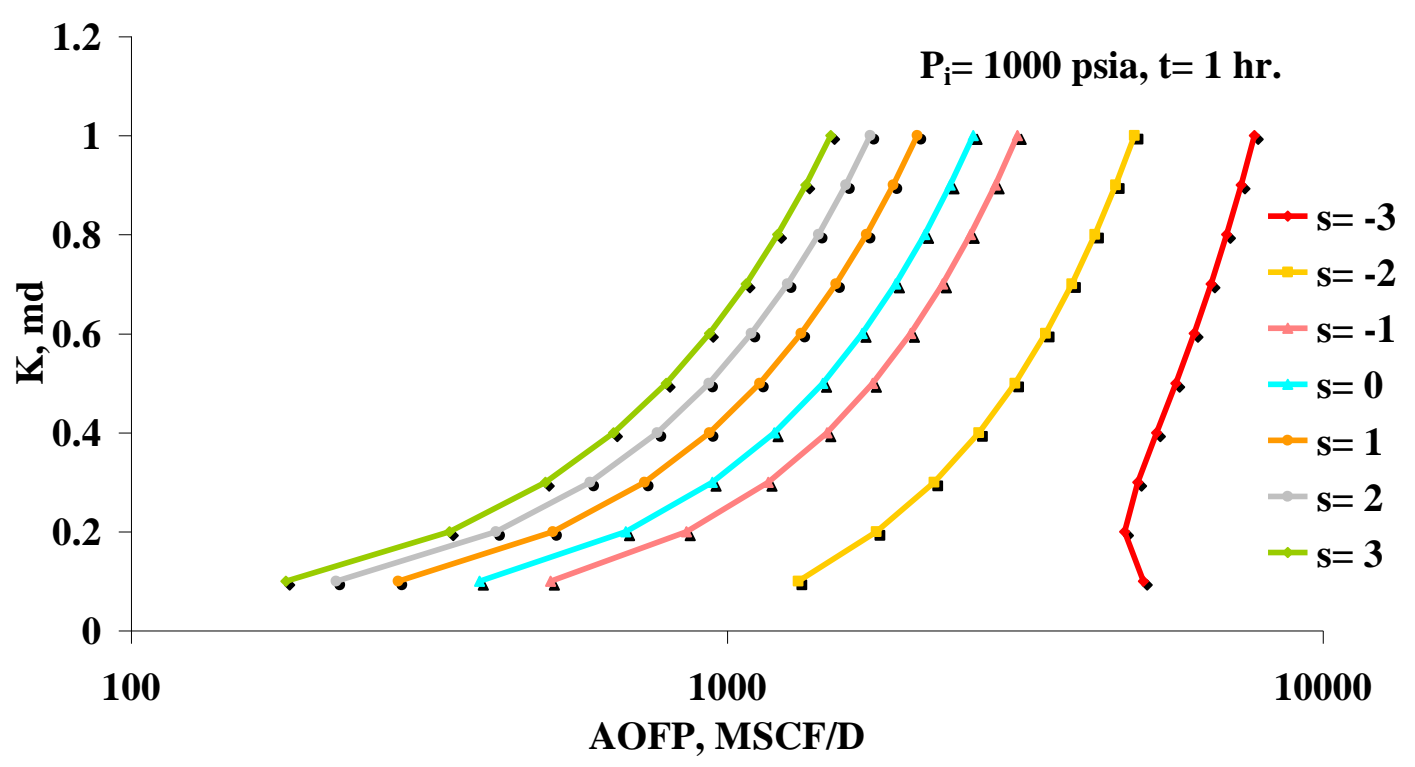

Figure 3.1: Permeability vs. AOF $P$ for $P_{i}=1000$ psia, $t=1$ hr, and $S=-3$ to 3

Permeability was plotted against AOFP, for different test duration as specified initial reservoir pressure and skin factor. Figure 4.2 (in the result section) illustrates the impact of time on AOFP for a particular range of permeability.

Permeability was plotted against AOFP, for various initial reservoir pressures, as specified skin factor and test duration as illustrated in Figure 3.2. 


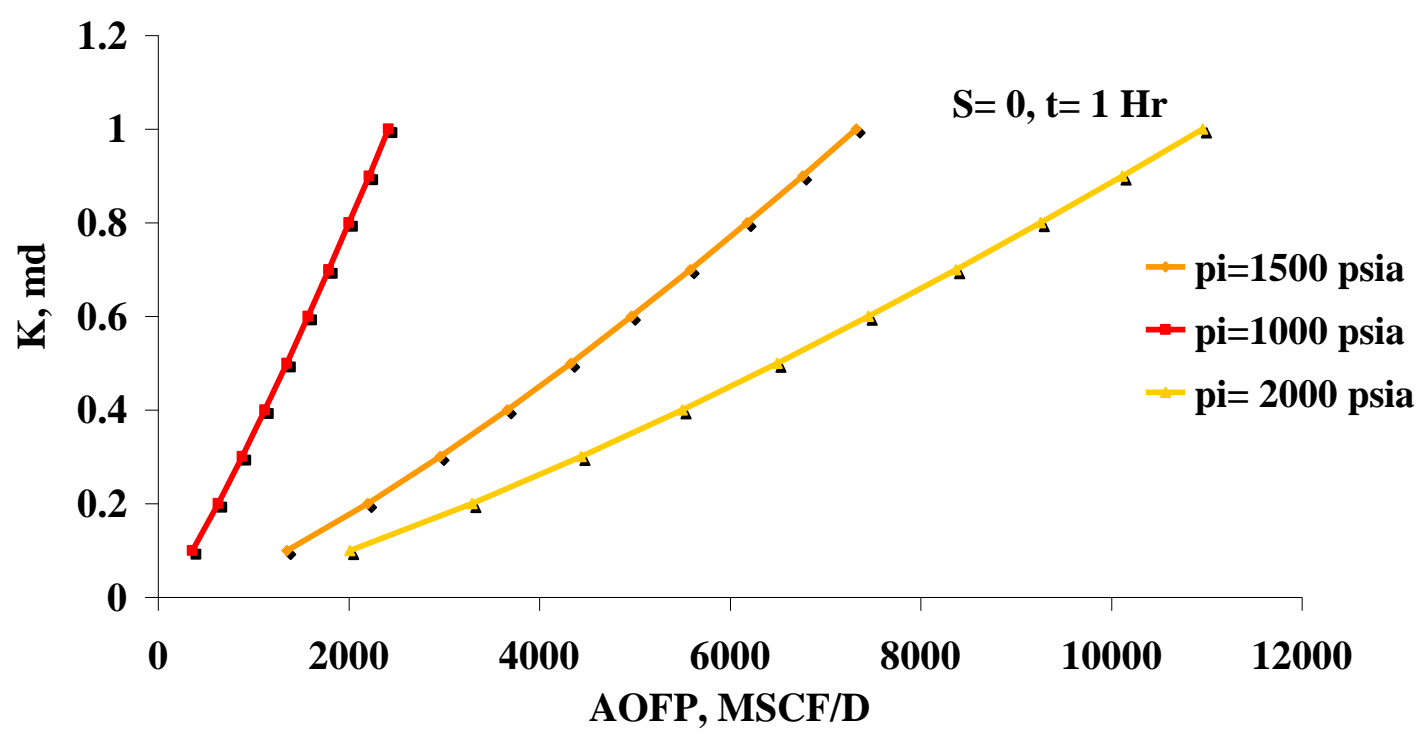

Figure 3.2: Permeability vs. AOFP for $P_{i}=1000,1500$, and 2000 psia

After showing the effect of skin factor, time and initial reservoir pressure on AOFP, using Logk +0.875 , a combined range (Refer to Table B-2 in the Appendix for range) was calculated. Then AOFP values were calculated for various initial reservoir pressures and non-Darcy flow coefficient respectively. Through out this study, Tek et al. non-Darcy coefficient (equation 9) was used in unsteady state transient radial flow equation to study the behavior of low permeability formation properties in Appalachian basin on AOFP. Tek et al. correlation is usually used for low permeability formation.

Logk + 0.87S was plotted against AOFP, for various initial reservoir pressures, as specified test duration as illustrated in Figure 4.3. 
Logk +0.875 was plotted against AOFP, for various non-Darcy coefficient, as specified test duration (Refer to Figure 4.4 in result section and Table B.2 in the Appendix B for tabulated result).

\subsection{I mpact of Skin Factor and Permeability on AOFP (Pseudo-Steady State R adial Flow)}

The second step of this study was to evaluate the impact of permeability and skin factor on AOFP using pseudo-steady state radial flow solution. To attain this goal, AOFP value was calculated using pseudo-steady state radial flow solution (See Equation 7). In order to find AOFP, the quadratic formula was used. To find all parameters of the quadratic formula, equation 7 was divided into three parts as following:

$$
\begin{gathered}
\mathrm{a}=\mathrm{D} \times \mathrm{C}_{1} \\
\mathrm{~b}=\mathrm{C}_{1} \times \ln \left(\frac{0.472 \mathrm{r}_{\mathrm{e}}}{\mathrm{r}_{\mathrm{w}}}\right)+\mathrm{S} \\
\mathrm{c}=-\mathrm{m}\left(\overline{\mathrm{p}_{\mathrm{r}}}\right)-\mathrm{m}\left(\overline{\mathrm{p}_{\mathrm{wf}}}\right)
\end{gathered}
$$

\section{Where}

$\mathrm{C}_{1}=\frac{1422 \mathrm{~T}}{\mathrm{kh}}$

In order to develop a correlation between permeability, skin factor and AOFP the following steps were utilized: 
AOFP values were calculated for permeability data range from 0.1 to 1 , keeping skin factor and reservoir pressure constant, then skin factor values were varied from -3 to 3 (Refer to Table B.1 in the Appendix B for tabulated result).

Permeability was plotted against AOFP for various skin factors at specified reservoir pressure as illustrated in figure 4.5 (Refer to result).

The skin factor was plotted against AOFP for various permeability values at specified reservoir pressure as illustrated in Figure 3.3.

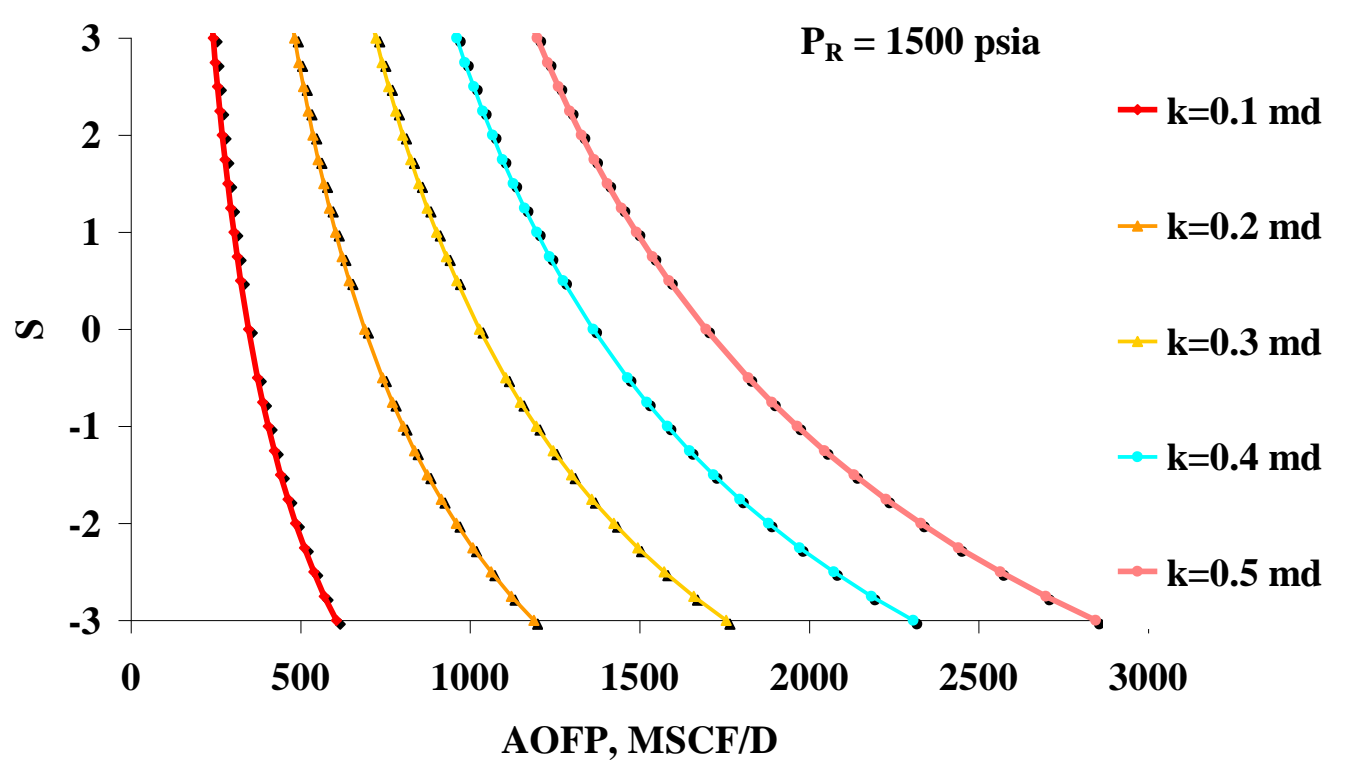

Figure 3.3: Skin Factor vs. AOF P for Various Permeability Values at $P_{R}=1500$ psia.

Permeability was plotted against AOFP for various reservoir pressures at specified skin factor and time duration as illustrated in figure 3.4. 


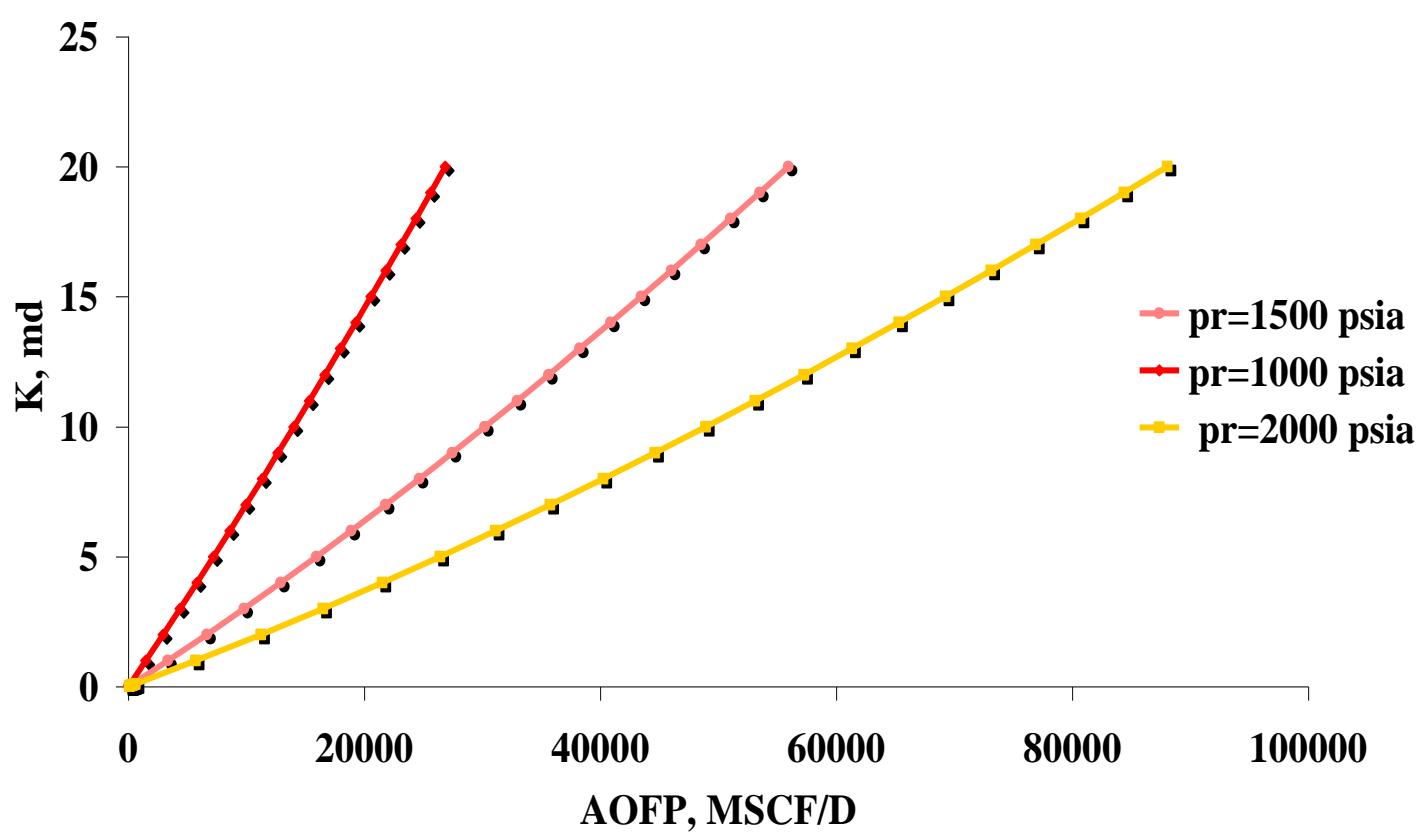

Figure 3.4: AOF P vs. Permeability for zero skin factor, $P_{R}=1000,1500$, and 2000 psia

\subsection{The I mpact of $\mathrm{H}$ ydraulic Fracture on Absolute $\mathrm{O}$ pen F low Potential (Bilinear Flow, D arcy and Non-D arcy)}

The third step of this study was to determine the AOFP based on analytical expression of bilinear flow regimes in finite conductivity fracture for Darcy and non-Darcy flow conditions. To attain this goal, following procedure was performed:

The dimensionless variable $\left(m_{D}\left(t_{D}\right), t_{d}\right.$, and $\left.C_{f_{d}}\right)$ from equations 21-23, were substituted in equation 17. By rearranging the terms in equation 17, the equation for AOFP in finite conductivity fracture under Darcy flow conditions is shown below (Refer to Appendix D, for derivation of AOFP):

$$
\mathrm{AOFP}=\frac{\mathrm{kh}\left[\mathrm{m}\left(\mathrm{p}_{\mathrm{i}}\right)-\mathrm{m}\left(\mathrm{p}_{\mathrm{wf}}\right)\right] \Gamma(5 / 4)\left(2 \mathrm{C}_{\mathrm{fD}}\right)^{\frac{1}{2}}}{\left(\pi \mathrm{t}_{\mathrm{D}}^{1 / 4}\right)(1422 \mathrm{t})}
$$


The dimensionless variable $\left(m_{D}\left(t_{D}\right), t_{d}, C_{f_{d}, a p p}\right.$ and $\left.q_{D N D}\right)$ from equations 21-25, were substituted in equation 18. Rearranging the terms in equation 18 gives the following equation (Refer to Appendix D, for derivation of AOFP):

$$
\begin{aligned}
& -(1422 \mathrm{~T})^{2} \quad 0.31 \quad 4.64 \quad 10^{-16}\left(\pi \mathrm{t}_{\mathrm{D}}^{\frac{1}{4}}\right)^{2} \mathrm{k}_{\mathrm{f}} \beta \mathrm{M} \mathrm{q} \mathrm{q}^{3}-(1422 \mathrm{~T})^{2} \mathrm{w}_{\mathrm{f}} \mathrm{h} \mu_{\mathrm{i}}\left(\pi \mathrm{t}_{\mathrm{D}}^{\frac{1}{4}}\right)^{2} \mathrm{q}^{2}+ \\
& {\left[\begin{array}{ll}
\Gamma(1.25)
\end{array}\right]^{2}\left[\begin{array}{lll}
\mathrm{kh} & \left\{\mathrm{m}\left(\mathrm{p}_{\mathrm{i}}\right)-\mathrm{m}\left(\mathrm{p}_{\mathrm{wf}}\right)\right\}
\end{array}\right]^{2}\left(2 \mathrm{C}_{\mathrm{fD}}\right) \mathrm{w}_{\mathrm{f}} \mathrm{h} \mu_{\mathrm{i}}=0}
\end{aligned}
$$

In order to find AOFP, cubic solution was used (see Appendix C). To find all parameters for cubic solution, equation 27 was divided into four parts:

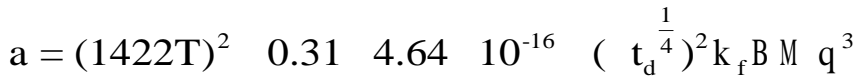

$$
\begin{aligned}
& \mathrm{b}=(1422 \mathrm{~T})^{2} \mathrm{w}_{\mathrm{f}} \mathrm{h} \mu_{\mathrm{i}}\left(\pi \mathrm{t}_{\mathrm{d}}^{\frac{1}{4}}\right)^{2} \mathrm{q}^{2} \\
& c=0 \\
& \mathrm{~d}=[\Gamma]^{2}\left[\mathrm{kh}\left(\mathrm{m}\left(\mathrm{p}_{\mathrm{i}}\right)-\mathrm{m}\left(\mathrm{p}_{\mathrm{wf}}\right)\right]^{2}\left(2 \mathrm{C}_{\mathrm{fd}}\right) \mathrm{w}_{\mathrm{f}} \mathrm{h} \mu_{\mathrm{i}}\right.
\end{aligned}
$$

In order to develop a correlation between permeability, dimensionless fracture conductivity and AOFP the following steps were utilized:

AOFP values were calculated using equation 27 for dimensionless fracture conductivity data range from 10 to 40, keeping initial reservoir pressure and time constant, then permeability values were varied from 0.1 to $0.5 \mathrm{md}$ (Refer to Table D. 1 in the Appendix D for tabulated result).

The dimensionless fracture conductivity was plotted against AOFP for various permeability values at specified initial reservoir pressure as illustrated in figure 3.5. 


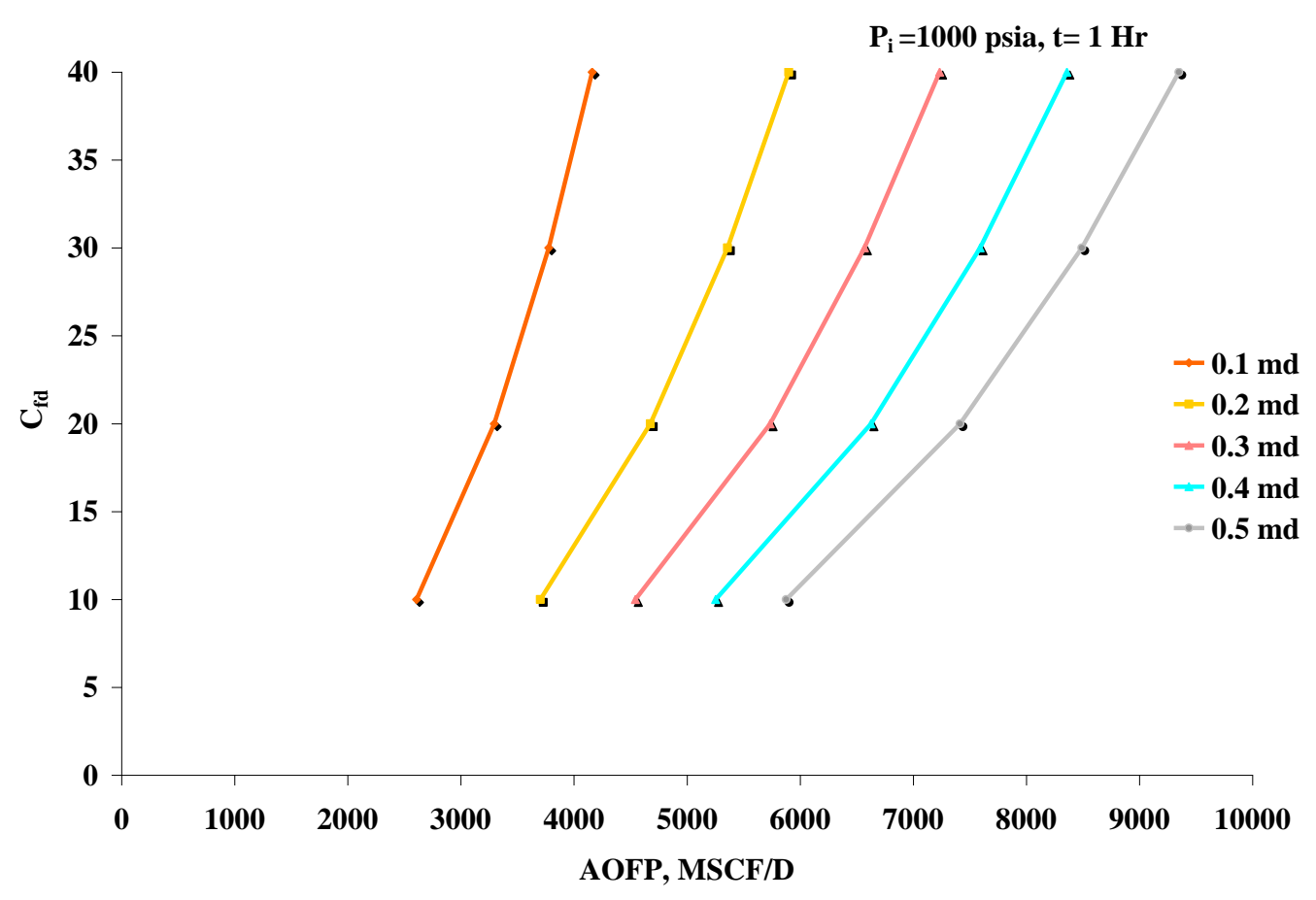

Figure 3.5: Dimensionless Fracture C onductivity vs. AOF P (for $P_{i}=1000$ psia, $\mathrm{t}=1 \mathrm{hr}$, and $\mathrm{k}=0.1$ to $0.5 \mathrm{md}$ )

The initial reservoir pressure was plotted against AOFP for various permeability values at specified test duration.

\subsection{The Impact of Hydraulic Fracture on AOFP (L inear Flow in Finite Conductivity Fracture Darcy and Non-D arcy)}

The $4^{\text {th }}$ step of this study was to determine the AOFP based on analytical expression of linear flow regimes in finite conductivity fracture for Darcy and non-Darcy flow conditions. To attain this goal, following procedure was performed:

For finite conductivity fracture under Darcy flow conditions, equation 19 was used to find the AOFP. The dimensionless variable $\left(m_{D}\left(t_{D}\right), t_{d}\right.$, and $\left.C_{f_{d}}\right)$ from 
equations 21-23, were substituted in equation 19. By rearranging the terms in equation 19, the equation for AOFP in finite conductivity fracture under Darcy flow conditions is shown below (Refer to Appendix D, for derivation of AOFP):

$$
\mathrm{AOFP}=\frac{\mathrm{C}_{\mathrm{fD}} \mathrm{kh}\left[\mathrm{m}\left(\mathrm{p}_{\mathrm{i}}\right)-\mathrm{m}\left(\mathrm{p}_{\mathrm{wf}}\right)\right]}{1422 \mathrm{TC}_{\mathrm{fD}}\left(\pi \mathrm{t}_{\mathrm{D}}\right)^{\frac{1}{2}}+1422 \mathrm{Ta}}
$$

The dimensionless variable $\left(m_{D}\left(t_{D}\right), t_{d}, C_{f_{d} \text { app }}\right.$ and $\left.q_{D N D}\right)$ from equations 21-25, were substituted in equation 20. Rearranging the terms in equation 20 gives the following equation (Refer to Appendix D, for derivation of AOFP).

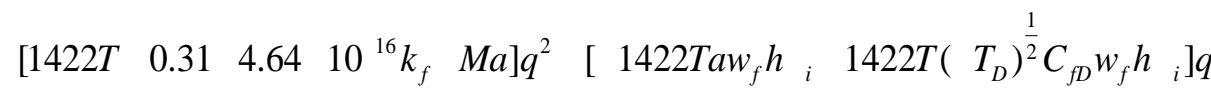

$$
\begin{aligned}
& \operatorname{kh}\left[m\left(p_{i}\right) \quad m\left(p_{w f}\right)\right] C_{f D} w_{f} h ; \quad 0
\end{aligned}
$$

AOFP value was calculated using quadratic formula. To find all parameter for the quadratic formula, equation 29 was divided in to three parts:

$$
\begin{gathered}
\mathrm{a}=-\left[1422 \times \mathrm{T} \times 0.31 \times 4.64 \times 10^{-16} \mathrm{k}_{\mathrm{f}} \times \beta \times \mathrm{M} \times \mathrm{a}\right. \\
\mathrm{b}=\left[-1422 \times \mathrm{T} \times \mathrm{a} \times \mathrm{w}_{\mathrm{f}} \times \mathrm{h} \times \mu_{\mathrm{i}}-1422 \times \mathrm{T} \times\left(\pi \times \mathrm{t}_{\mathrm{D}}\right)^{1 / 2} \times \mathrm{C}_{\mathrm{fD}} \times \mathrm{w}_{\mathrm{f}} \times \mathrm{h} \times \mu_{\mathrm{i}}\right] \\
\mathrm{c}=\mathrm{k} \times \mathrm{h}\left[\mathrm{m}\left(\mathrm{p}_{\mathrm{i}}\right)-\mathrm{m}\left(\mathrm{p}_{\mathrm{wf}}\right)\right] \times \mathrm{C}_{\mathrm{fD}} \times \mathrm{w}_{\mathrm{f}} \times \mathrm{h} \times \mu_{\mathrm{i}}
\end{gathered}
$$

In order to develop a correlation between permeability, dimensionless fracture conductivity and AOFP the following steps were utilized:

AOFP values were calculated using equation 29 for dimensionless fracture conductivity data range from 10 to 100 , keeping initial reservoir pressure and time constant, then 
permeability values were varied from 0.1 to $0.5 \mathrm{md}$ (Refer to Table D.2 in the Appendix D for tabulated result).

Dimensionless fracture conductivity was plotted against AOFP for various permeability values at specified initial reservoir pressure.

Initial reservoir pressure was plotted against AOFP for various permeability values at specified test duration.

\subsection{I mpact of T ime on AO FP for L inear, Bilinear and R adial F low}

The $5^{\text {th }}$ step of this study was to determine a correlation between AOFP and time for linear, bilinear and radial flow solutions with identical skin factor. To attain this goal, following procedure was performed:

$\mathrm{C}_{\mathrm{fd}}$ values were converted to skin factor in linear and bilinear flow regime, for comparison purposes with radial flow regime, using Figure 2.2.

AOFP was plotted against test duration at specified initial reservoir pressure, permeability and skin factor, for bilinear (Darcy and non-Darcy) and radial flow (non-Darcy) comparison.

AOFP was plotted against test duration at specified initial reservoir pressure, permeability and skin factor, for linear (Darcy and non-Darcy) and radial flow (non-Darcy) comparison (For tabulated result refer to Appendix D). 


\section{CHAPTER IV}

\section{RESULTS AND DISCUSSION}

The main objective of this study was to determine the formation properties of low permeability formation from AOFP. To achieve this objective, several different solutions were considered to determine the relationship between AOFP, permeability, and skin factor.

The first step of analysis is the impact of skin factor, permeability, and initial reservoir pressure, on AOFP using unsteady state transient radial flow equation. Figure 4.1 illustrates the impact of skin factor on relationship between permeability and AOFP.

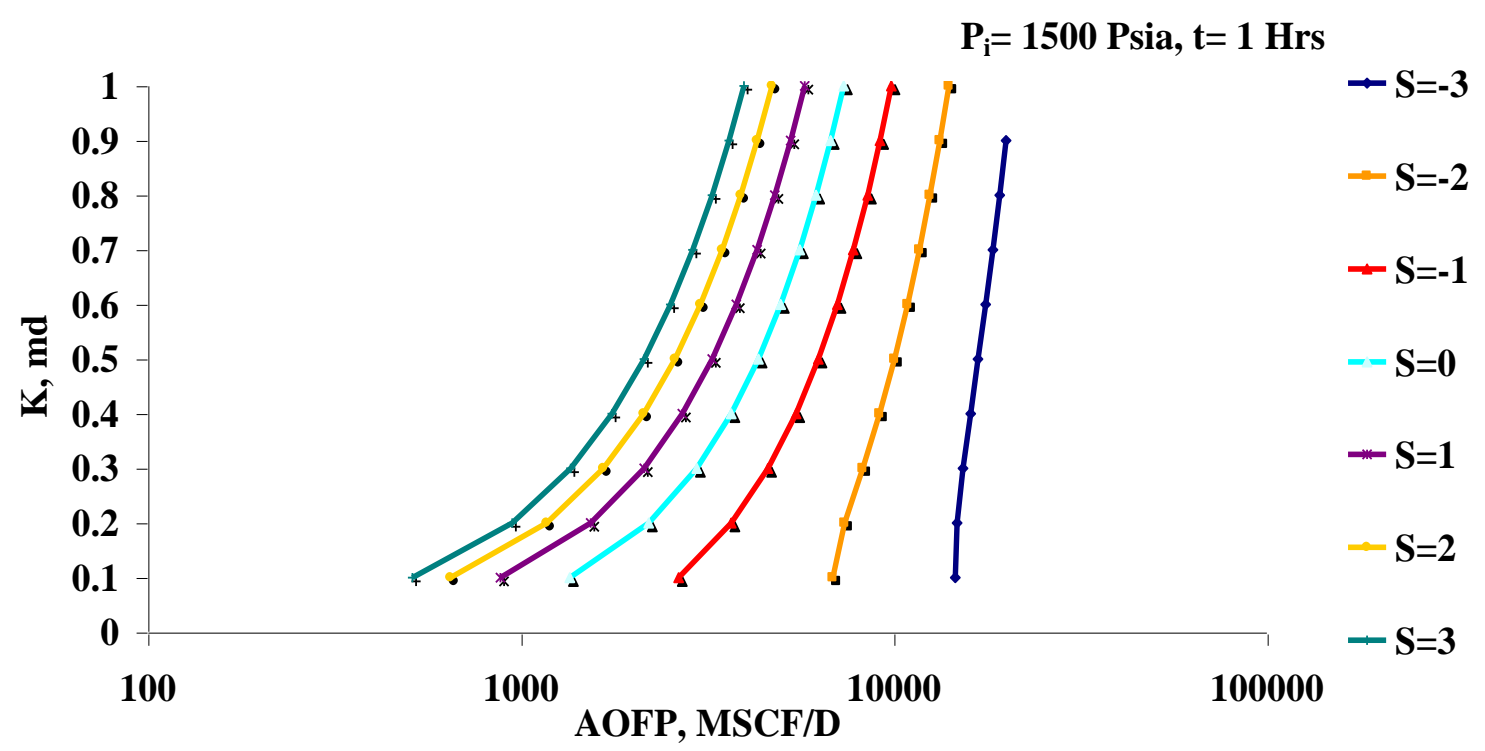

Figure 4.1: Per meability vs. AOFP for $\left(P_{i}=1500 \mathrm{psi}, t=1 \mathrm{hr}\right.$, and $S=-3$ to 3$)$

Figure 4.1, illustrates that as skin factor decreases within the ranges of -3 to 3 , the curve shift to the right. For negative skin factor the permeability does not have significant 
impact on AOFP (non-Darcy). However for positive skin factor lower permeability values have some impact on AOFP (non-Darcy).

From Figure 4.1, it is possible to predict permeability values for skin factor range of -3 to 3 and AOFP range of 0 to $25000 \mathrm{MSCF} / \mathrm{D}$ (Refer to Figure B-1 in Appendix for pressure 2000 psia).

Figure 4.2 shows the correlation between permeability and AOFP, for skin factor of 0 , time range of 1 to 3 hours, and initial reservoir pressure of 1500 psia.

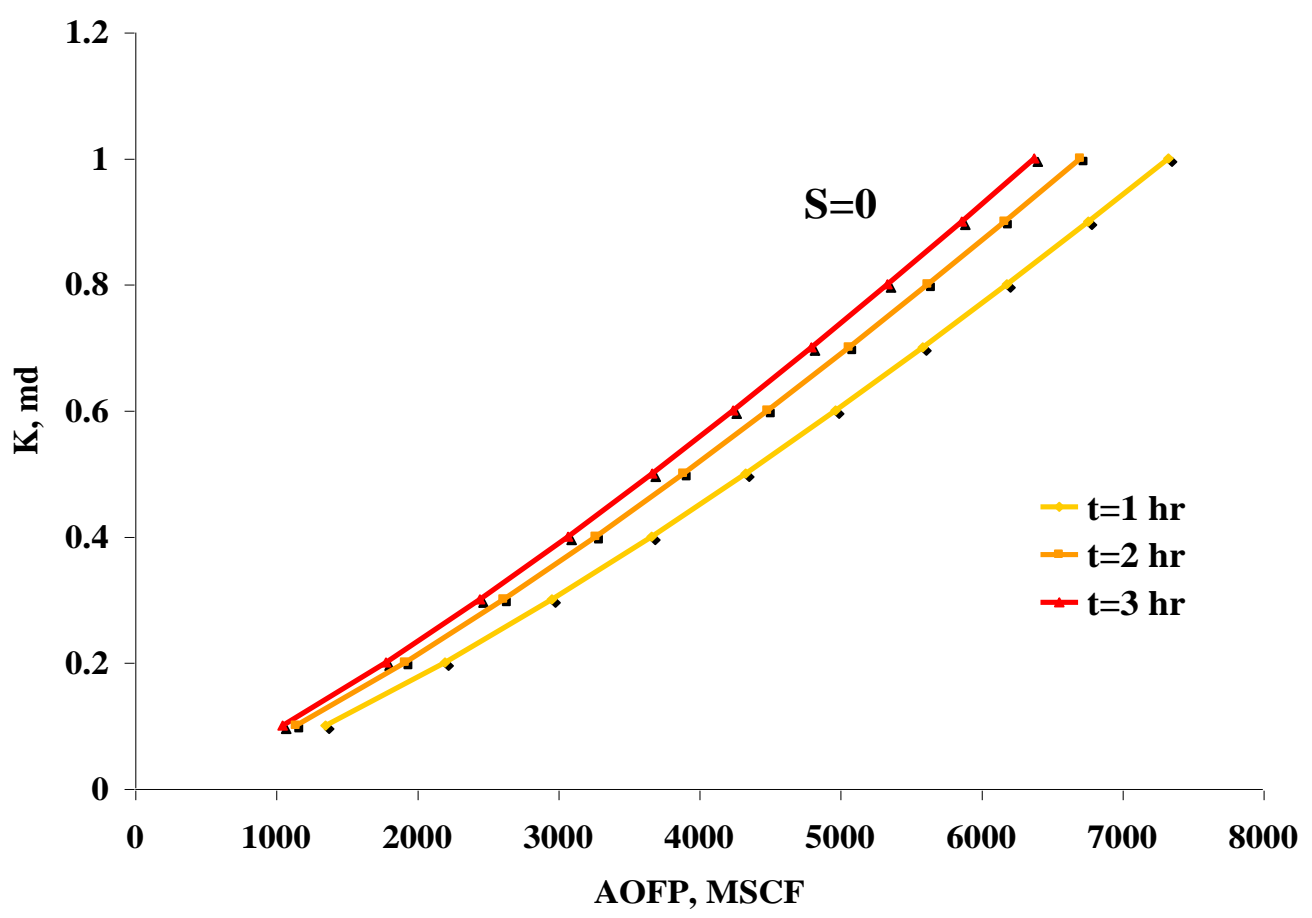

Figure 4.2: Permeability vs. AOFP for $P_{i}=1500$ psia and $t=1,2,3$ hrs

Figure 4.2, illustrates that, time does not have significant impact on AOFP (non-Darcy) using unsteady state transient radial flow solution for low permeability range of 0.1 to1 md. 


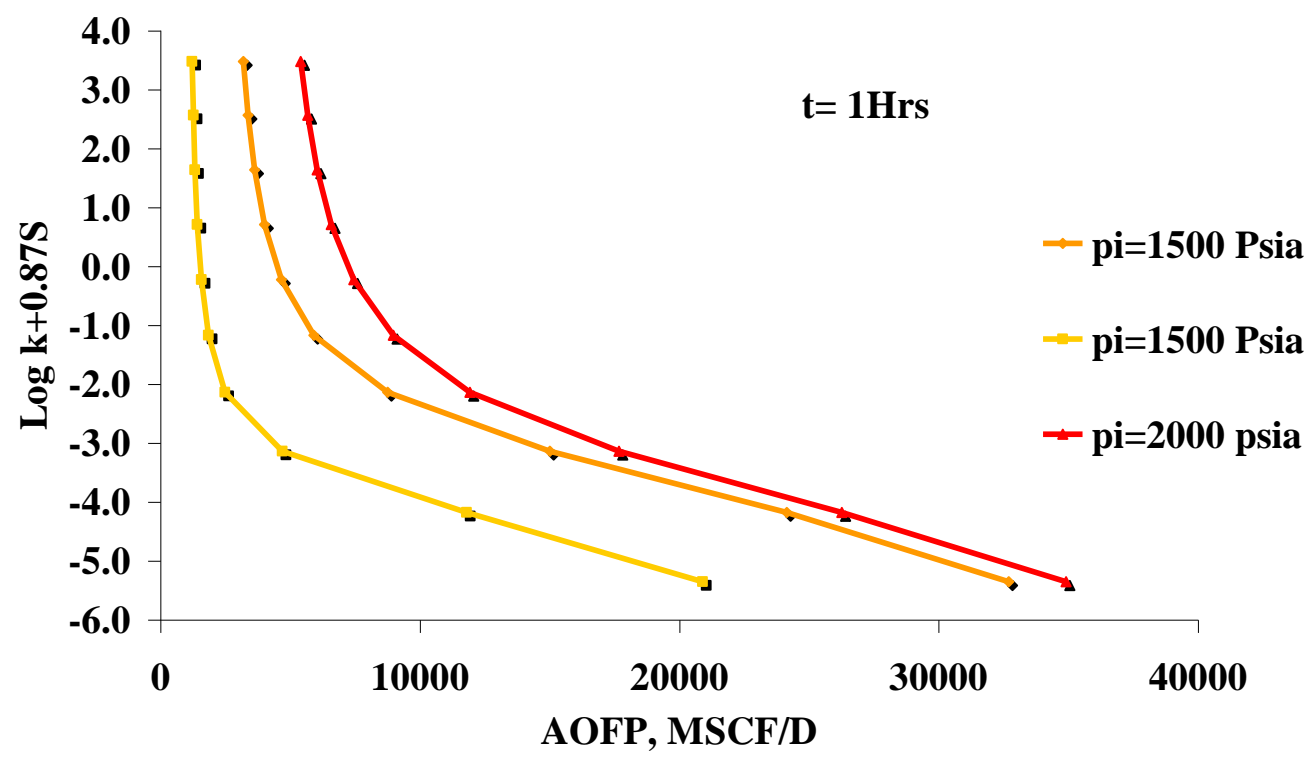

Figure 4.3: $\log K+0.87 S$ vs. AOF $P$ for $P_{i}=1000,1500$, and 2000 psia

Figure 4.3, a graph of $\operatorname{LogK}+0.875$ vs. AOFP shows the relationship between permeability, skin factor, and AOFP. From Figure 4.3, Permeability can be predicted, assuming skin factor is known for initial reservoir pressure of 1000, 1500, and 2000 psia respectively.

Figure 4.4, shows the different non-Darcy coefficient $(\beta)$ correlation, and how they impact the AOFP. Janicek and Katz correlation is typically used for sandstone formation. Similar to Jones non-Darcy coefficient ( ) correlation, Coles, and Hartman correlation is commonly used for different core types such as limestone and fine grain sandstone (high permeability) formation. Pascal et al. non-Darcy coefficient ( ) correlation is used for low permeability fractured formation. 


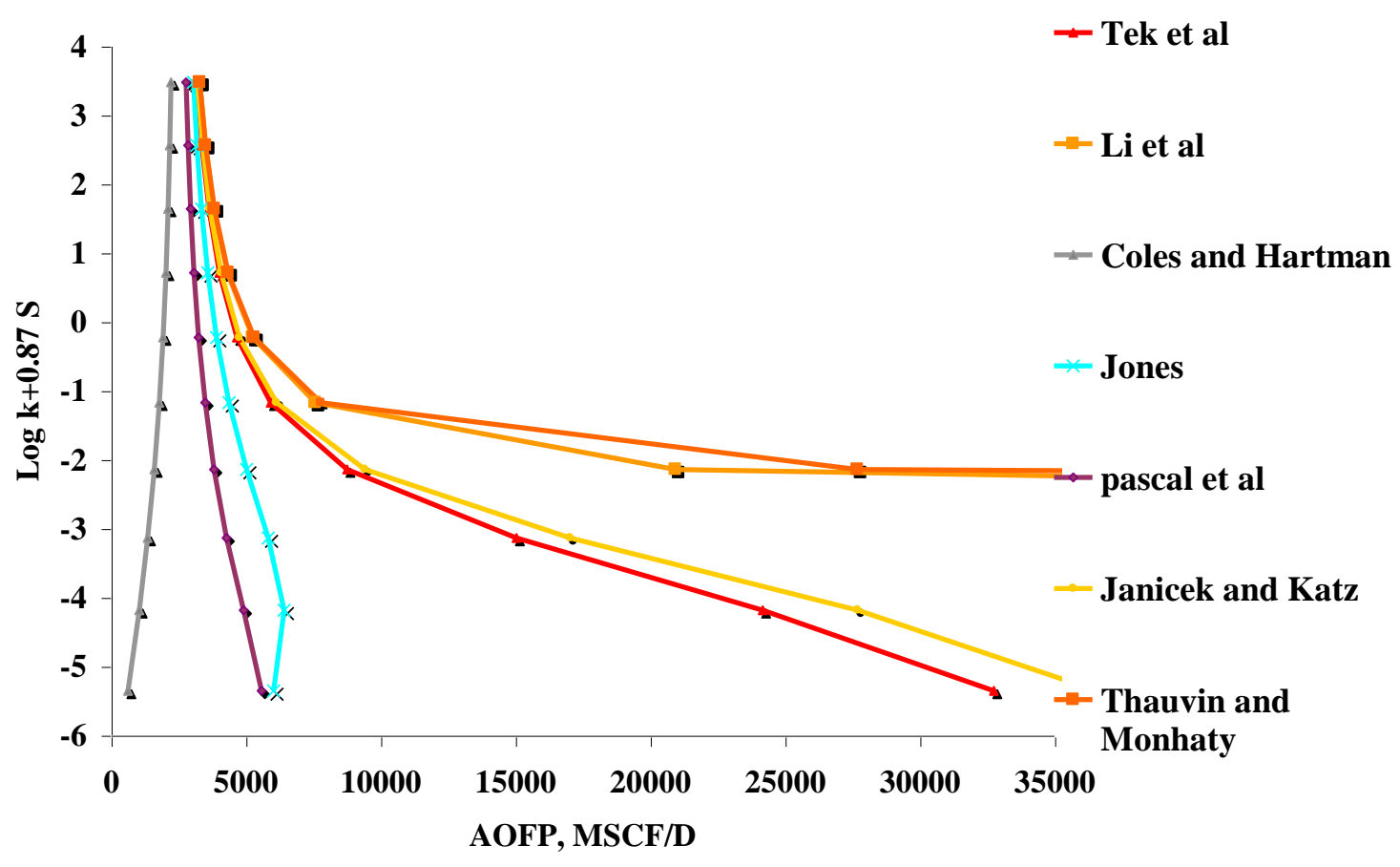

Figure 4.4: $\log K+0.87 S$ vs. AOF P for (different $\beta$ correlation)

Figure 4.4, shows that for negative skin factor ( $\log K+0.875 \quad 0)$, the AOFP (non-Darcy) differs for various non-Darcy coefficient ( ) correlation. However for positive skin factor $(\log \mathrm{K}+0.87>0)$, the AOFP (non-Darcy) acts similarly for various non-Darcy coefficients ( ) correlation.

From figure 4.4, it is also possible to read permeability value for different non-Darcy coefficient ( ) correlation based on the formation of interest, having the value of skin factor.

The next step was to evaluate the impact of skin factor and permeability on AOFP using pseudo-steady state equation. Figure 4.5 illustrates that there is linear relationship 
between permeability and AOFP for various skin factors. Furthermore unlike unsteady state solution permeability does not have significant impact on AOFP (non-Darcy).

Skin effect can be negative due to stimulation, which means more production. Due to damage the skin effect could be positive which means less production. As the fluid gets close to the wellbore, there is a decrease in the permeability and positive skin factor.

Permeability can be estimated from using pseudo-steady state equation assuming the known value of the skin factor for AOFP (Refer to Table C-1 in the Appendix C for tabulated result).

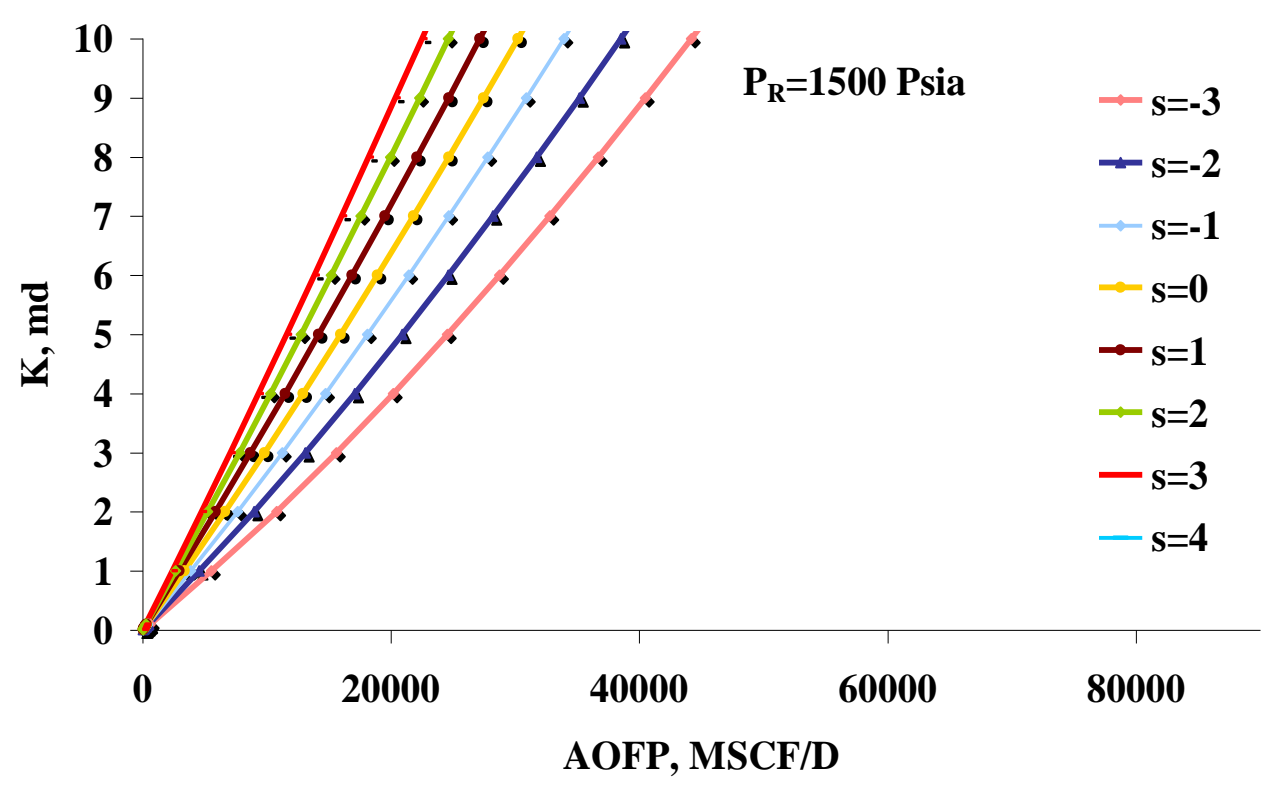

Figure 4.5: Permeability vs. AOFP for $P_{R}=1500$ Psia.

Since most low permeability gas wells are hydraulically fractured to improve their productivity. The impact of hydraulic fracture on absolute open flow potential was evaluated using bilinear flow solution in finite conductivity fracture (non-Darcy). 
Figure 4.6 illustrates the impact of permeability on relationship between dimensionless fracture conductivity and AOFP.

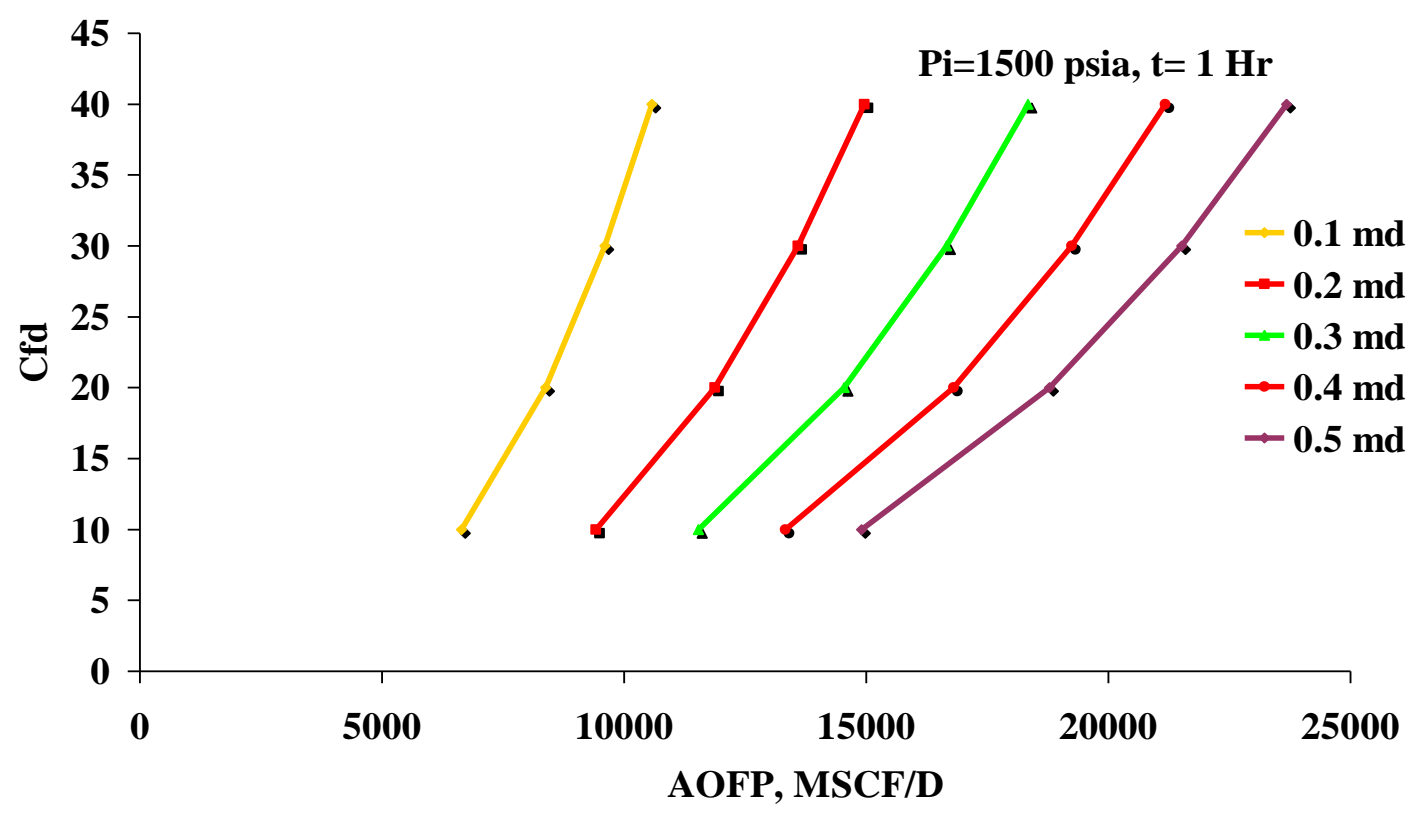

Figure 4.6: Dimensionless Fracture C onductivity vs. AOFP $\left(P_{i}=1500\right.$ psia, $t=1 \mathrm{hr}$, and $k=0.1$ to $\left.0.5 \mathrm{md}\right)$

From Figure 4.6, it is possible to predict dimensionless fracture conductivity values for permeability range of 0.1 to $0.5 \mathrm{md}$ and AOFP range of 0 to $25000 \mathrm{MSCF} / \mathrm{D}$.

Figure 4.7 illustrates the impact of permeability on relationship between initial reservoir pressure and AOFP using bilinear flow solution in finite conductivity fracture. 


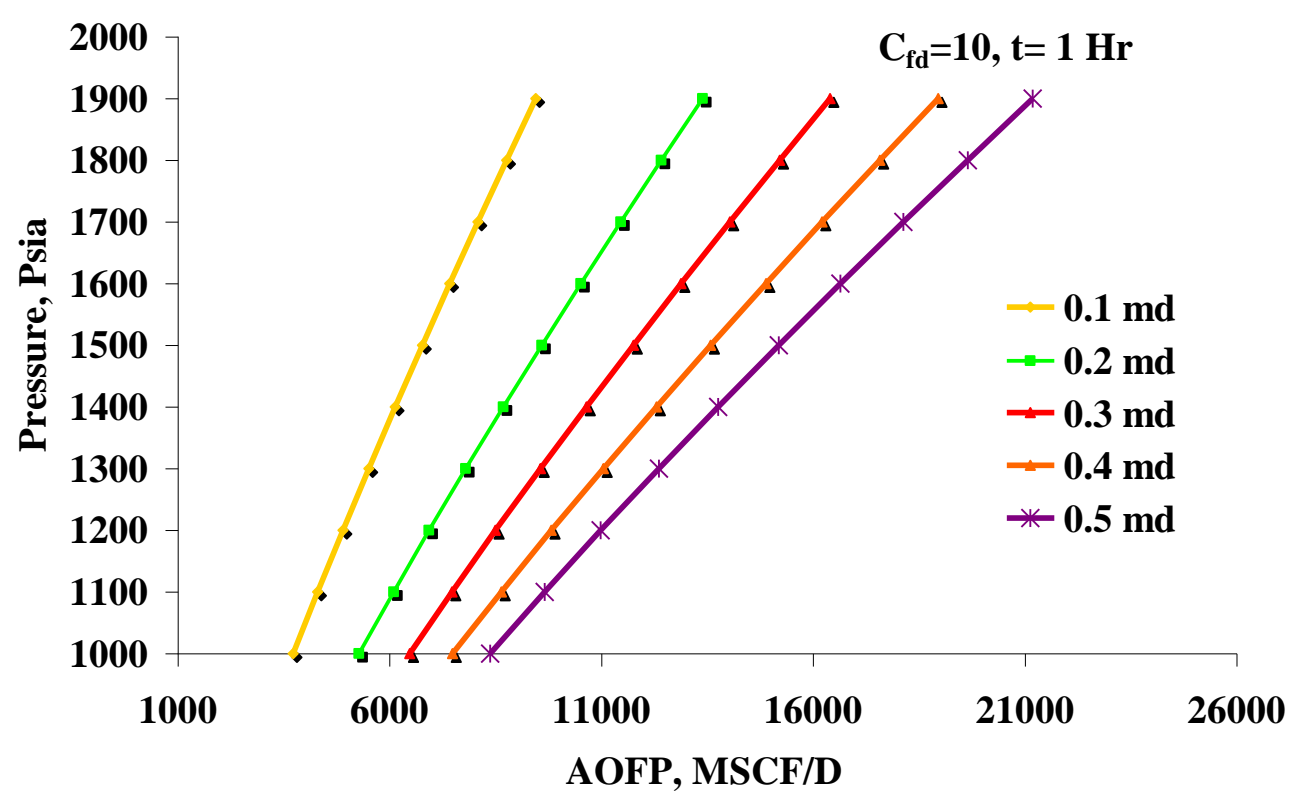

Figure 4.7: Initial Reservoir Pressure vs. AOFP for $C_{f d}=10$ and $t=1 \mathrm{hr}$

From Figure 4.7, it is possible to predict initial reservoir pressure values for permeability range of 0.1 to $0.5 \mathrm{md}$, AOFP range of 4000 to $21000 \mathrm{MSCF} / \mathrm{D}$.

The next step was to evaluate the impact of hydraulic fracture on absolute open flow potential using linear flow solution in finite conductivity fracture (non-Darcy).

Figure 4.8 illustrates the impact of permeability on relationship between dimensionless fracture conductivity and AOFP. 


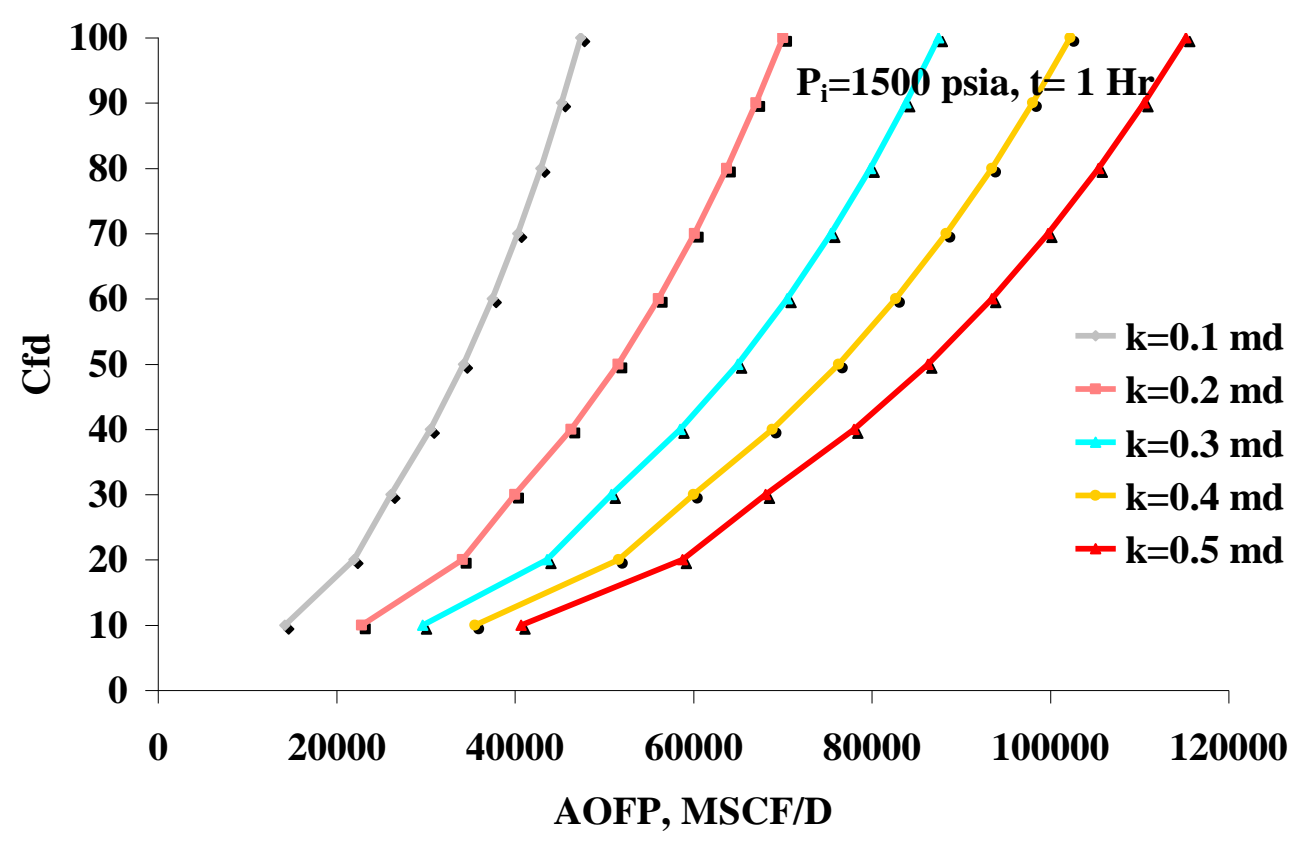

Figure 4.8: Dimensionless Fracture C onductivity vs. AOF P $\left(P_{\mathrm{i}}=\mathbf{1 5 0 0} \mathrm{psia}\right.$ and $\mathrm{t}=\mathbf{l h r}$ )

In the final step of this study, $\mathrm{C}_{\mathrm{fd}}$ values were converted to skin factor in linear and bilinear flow regime. Furthermore, skin factor for linear and bilinear flow were adjusted for comparison purpose with radial flow regime.

Figure 4.9 illustrates a correlation between AOFP and time for bilinear (Darcy and nonDarcy) and radial flow (non-Darcy) comparison using adjusted skin factor $\left(\mathrm{p}_{\mathrm{i}}=1500, \mathrm{t}=1\right.$, $2,4 \mathrm{hrs}, \mathrm{S}=-4.24)$. 


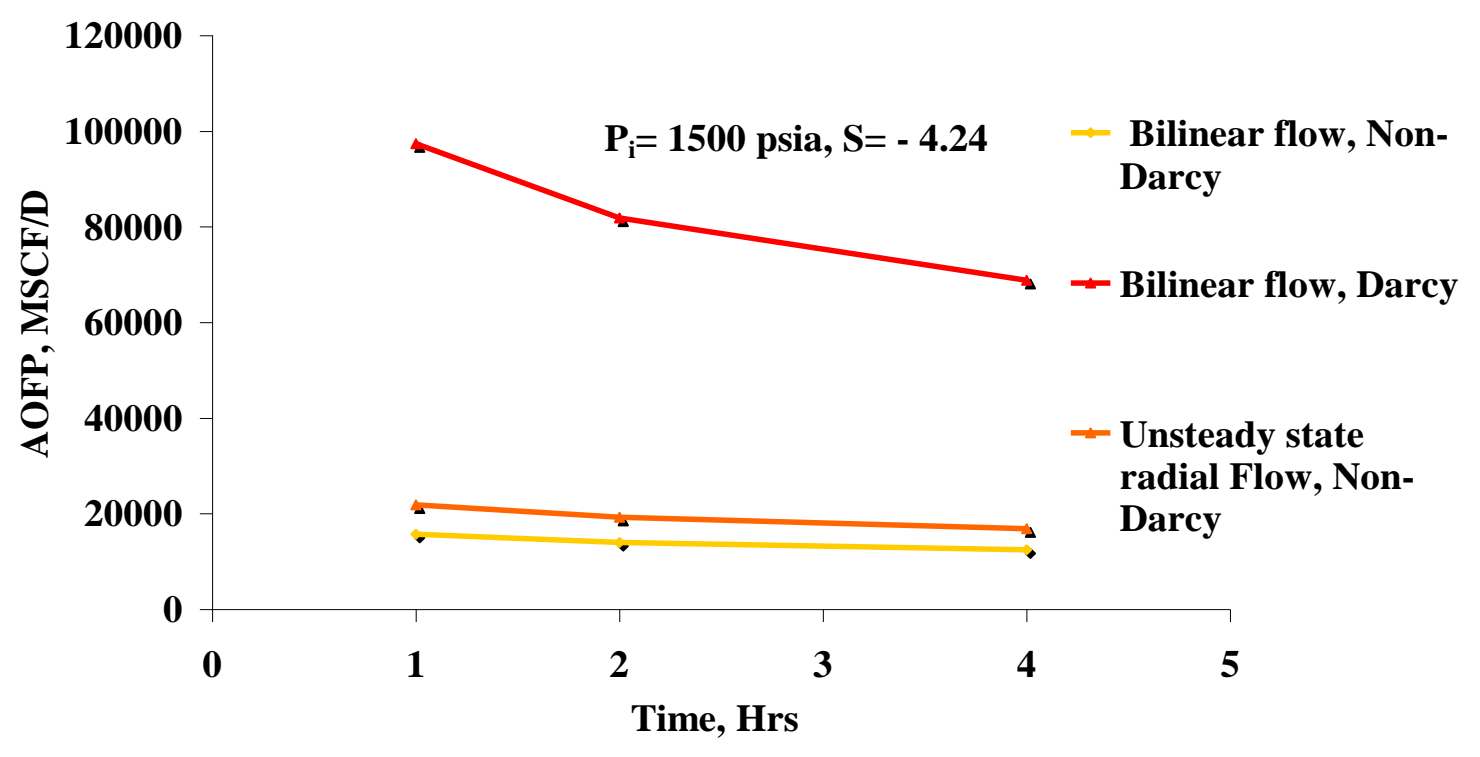

Figure 4.9: AOFP vs. T ime for Bilinear Flow

$\left(P_{i}=1500\right.$ psia, $K=0.5 \mathrm{md}$, and $\left.S=-4.24\right)$

Figure 4.10 illustrates a correlation between AOFP and time for bilinear (Darcy and nonDarcy) and radial flow (non-Darcy) comparison using adjusted skin factor $\left(\mathrm{p}_{\mathrm{i}}=2000, \mathrm{t}=1\right.$, $2,4 \mathrm{hrs}, \mathrm{S}=-4.24)$.

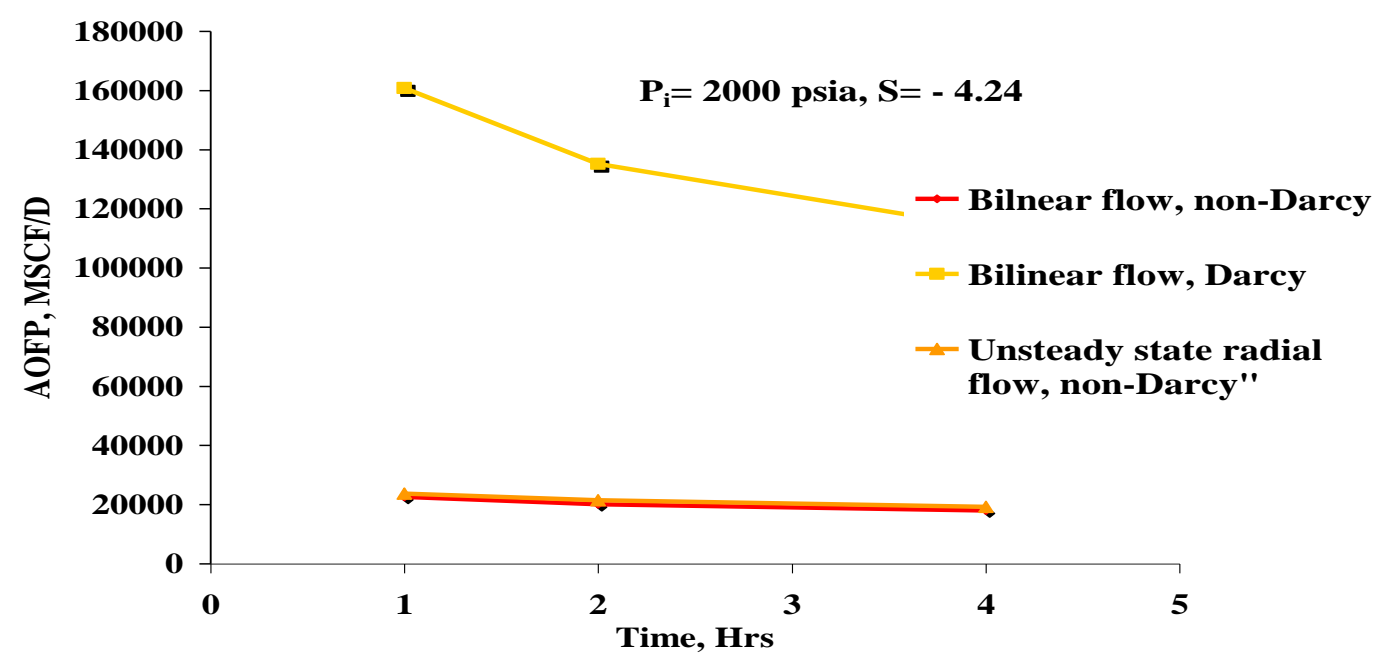

Figure 4.10: AOFP vs. Time for Bilinear Flow

$\left(P_{\mathrm{i}}=2000 \mathrm{psia}, \mathrm{K}=0.5 \mathrm{md}\right.$, and $\left.\mathrm{S}=\mathbf{- 4 . 2 4}\right)$. 
Figure 4.10 shows that for pressure of 2000 psia, radial flow curve (non-Darcy) is close to bilinear flow (non-Darcy) which indicates that using unsteady state radial flow equation for adjusted skin factor, leads to reasonable estimate of AOFP (non-Darcy). Also, linearity of these two curves (bilinear and radial flow) illustrates that time does not have significant impact on non-Darcy AOFP.

Figures 4.9 and 4.10 show that as pressure increase, the difference between radial and bilinear flow for (non-Darcy) condition decrease.

Figure 4.11 shows a correlation between AOFP and time for linear (Darcy and nonDarcy) and radial flow (non-Darcy) comparison using adjusted skin factor $(\mathrm{P}=1500$, $\mathrm{K}=0.5 \mathrm{md}, \mathrm{t}=1,2,4 \mathrm{hrs}$, and $\mathrm{S}=-5.94)$.

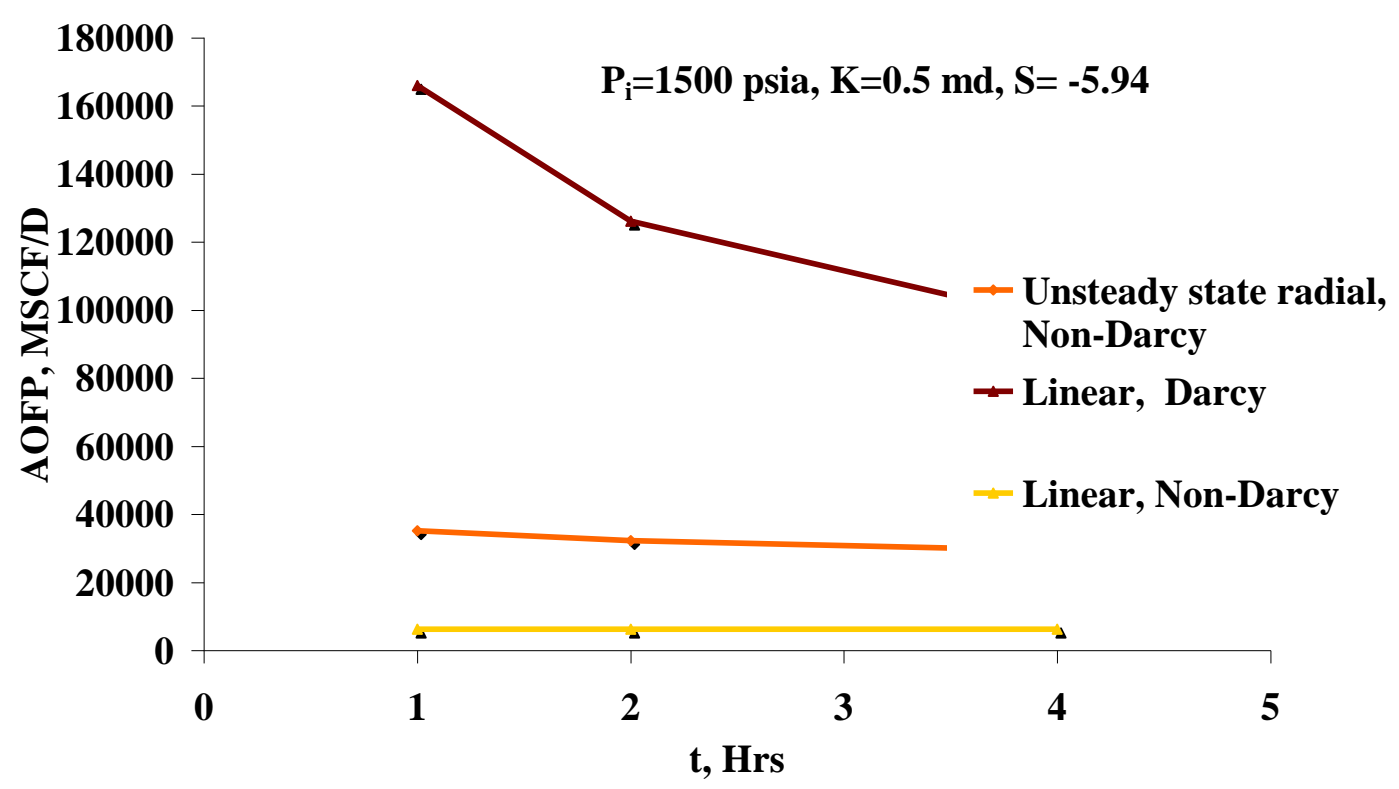

Figure 4.11: AOFP vs. Time for $L$ inear Flow $(P=1500, K=0.5 \mathrm{md}$ and $S=-5.94)$. 
Figure 4.11 shows that time does not have significant impact on AOFP for both linear and radial (non-Darcy) flow.

Figure 4.12 shows a correlation between AOFP and time for linear (Darcy and nonDarcy) and radial flow (non-Darcy) comparison using adjusted skin factor $(\mathrm{P}=1500$, $\mathrm{K}=0.1 \mathrm{md}, \mathrm{t}=1,2,4 \mathrm{hrs}$, and $\mathrm{S}=-5.94)$.

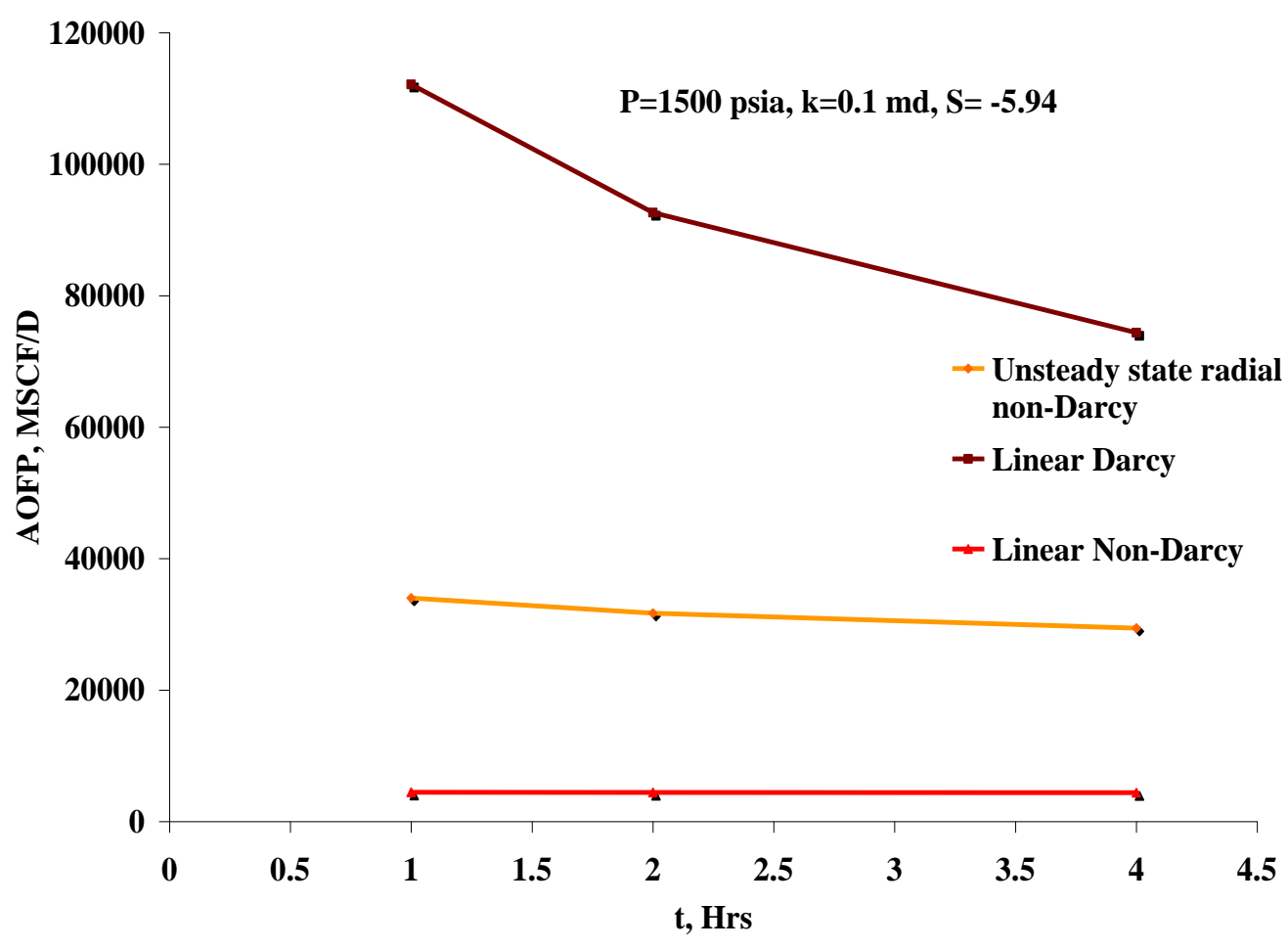

Figure 4.12: AOFP vs. Time for $L$ inear Flow

$$
(P=1500, K=0.1 \mathrm{md} \text { and } S=-5.94) \text {. }
$$

Figures 4.11 and 4.12 illustrate that as permeability increase, the difference between radial and bilinear flow for (non-Darcy) condition decrease. 


\section{CHAPTER V \\ CONCLUSIONS AND RECOMMENDATIONS}

After studying and analyzing the impact of skin factor and permeability on AOFP, the following conclusions have been reached in this study:

1. Correlation between permeability and AOFP have been developed using unsteady state and pseudo-steady state solutions.

2. The plot of AOFP vs. time illustrates that time does not have significant impact on bilinear, linear and radial flow solutions.

3. Transient radial flow equation can give a reasonable estimate of AOFP in fractured formation as compared to radial flow solution. As pressure increase, the difference between radial and bilinear flow for (non-Darcy) condition decrease. Furthermore, as permeability increase, the difference between radial and linear flow for (non-Darcy) condition decrease.

Non-Darcy coefficient is an important parameter that has significant impact in result of this study. It is recommended to study this parameter in detail in developing correlation between AOFP, permeability, and skin factor. 


\section{REFERENCES}

Al-Hussainy, R. and Ramey, H.J., Jr.: Application of Real Gas Flow Theory to Well Testing and Deliverability Forecasting,’Trans., AIM (1966) 237.

Alvarez, C., Holditch, S., and McVay, D., "Effects of Non-Darcy Flow on Pressure Transient Analysis of Hydraulically Fractured Gas Wells” SPE 77468-MS, presented at 2000 Annual Technical Conference and Exhibition, San Antonio, Texas, USA, 29 September 29 - October 2, 2000.

Aminian, K., “PNGE 470 Natural Gas Engineering” Reservoir Property Computer Programs, West Virginia University, 2003.

Chase, R.W., Alkandari, H., "Prediction of Gas Well Deliverability from a Pressure Buildup or Drawdown Test” SPE 26915, presented at 1993 SPE regional conference, PA, WV, USA, 2-4 November 1993

Camacho-V., R. G.: Response of Wells Producing Commingled Reservoirs: Unequal Fracture Length, MS Thesis, The University of Tulsa, Tulsa, OK (1984)

Cinco, H., Samaniego, F.: "Transient Pressure Analysis for Fractured Wells", J. Pet. Tech., (September 1981). 
Cinco, H., Samaniego, F.: "Transient Pressure Analysis: Finite Conductivity Fracture Case Versus Damaged Fracture Case", paper SPE 10179 presented at the 6th SPE

Cinco-Ley, H., F. Samaniego-V, and N. Dominguez-A. (1978). “Transient Pressure Behavior for a Well with a Finite Conductivity Vertical Fracture,” Society of PetroleumEngineers Journal.

Cornell, D. and Katz, D.L.: "Flow of Gases through Consolidated Porous Media," Industrial and Engineering Chemistry (Oct. 1953) 45, 2145.

Coles, M.E., and Hartman, K.J.: "Non-Darcy Measurements in Dry Core and the Effect of Immobile Liquid," paper SPE 39977.

Cooke, C.E., Jr.: "Conductivity of Fracture Proppants in Multiple Layers," JPT (1973), $1101-1107$.

Dacun, L., “Analytical Study of the Wafer Non-Darcy Flow Experiments,” SPE 76778, presented at 2000 Western Regional/AAPG Pacific Section Joint Meeting, Anchorage, Alaska, May, 20-22, 2000.

Ergun, S. and Orning, A.A.: "Fluid Flow through Randomly Packed Collumns and Fluidized Beds," Industrial and Engineering Chemistry (1949) 41, No. 6, 1179-1184. 
Forchheimer, P.: "Wasserbewewegung durch Boden," ZVDI(1901) 45, 1781.

Frederick Jr., D.C. and Graves, R.M.: "New Correlations To Predict Non-Darcy Flow Coefficients at Immobile and Mobile Water Saturation," paper SPE 28451 presented at the 1994 SPE Annual Technical Conference and Exhibition, New Orleans, Sept. 25-28.

Geertsma, J.: "Estimating the Coefficient of Inertial Resistance in Fluid Flow through Porous Media," SPEJ (Oct. 1974) 445-450.

Gil, J.A., Ozkan, E., Raghvan, R., "Fracture Well Test Design and Analysis in the Presence of Non-Darcy Flow” SPE71573, presented at 2001 Annual Technical Conference and Exhibition, San Louisiana, New Orleans, USA, 30 September- 3 October $2,2001$.

Gringarten, A.C., Ramey, H.J., JR., and Raghavan, R. (1974). “Unsteady-state pressure distributions created by a well with a single infinite-conductivity vertical fracture”. SPEJ., Aug., 347-360

Guppy, K. H., Cinco-Ley, H., Ramey, Jr. H. J., and Sameniego V., F.: “Non-Darcy Flow in Wells with Finite-Conductivity Vertical Fractures” SPEJ (Oct. 1982) 681

Guppy, K. H., Cinco-Ley, H., and Ramey, Jr. H. J.: "Pressure Buildup Analysis of Fractured Wells Producing at High Flow Rates, JPT (Nov. 1982) 2656. 
Guppy, K. H., Cinco-Ley, H., Ramey, Jr. H. J., and Sameniego-V., F.: “Non-Darcy Flow in Wells with Finite-Conductivity vertical Fractures” SPEJ (Oct. 1982) 681.

Houpeurt A., “On the flow of gases in porous media”, Revue de l'Institut Francais du petrole, XIV, (11),pp. 1468-1684, 1959.

Horne, Roland N., “Modern Well Test Analysis,” Stanford University.

Holditch, S. A. and Morse, R. A.: “The Effects of Non-Darcy Flow on the Behavior of Hydraulically Fractured Gas Wells,” JPT (Oct. 1976) 1169

Lee, W., Kuo, T., Holditch, S., Mcvay, D., and Holditch, S., "Estimating Formation Permeability From Single-Point Flow Data,” SPE 12847.

Lie et al., “A Review of the Methods of Estimating Stabilized Absolute Open-Flow Potential of Gas Wells” SPE 17308

Janicek, J.D., and Katz, D.L.: "Applications of Unsteady State Gas Flow Calculations," Proc., U. of Michigan Research Conference, June 20, 1955.

Jones, S.C.: "Using the Inertial Coefficient, to Characterize Heterogeneity in Reservoir Rock," paper SPE 16949 presented at the 1987 SPE Annual Technical Conference and Exhibition, 
Katz, D. L., Cornell, D., Kobayashi, R., Poettmann, F. H., Vary, J. A., Elenbaas, J. R. and Weinaug, C. F.: Handbook of Natural Gas Engineering, McGraw-Hill Book Co. Inc., New York, 1959.

Li, Dacun., Englar, TW, “Literature Review on Correlations of Non-Darcy Coefficient” SPE 70015, presented at SPE Permian Basin Oil and Gas Recovery conference, Midland, Texas, USA, 15-16 May 2001.

Li, D., Svec, R.K., Engler, T.W., and Grigg, R.B.: "Modeling and Simulation of the Wafer Non-Darcy Flow Experiments,” paper SPE 68822, Proc., the 2001 SPE Western Regional Meeting, Bakersfield, CA, March 26-30.

Millheim, K. K. and Cichowicz, L.: “Testing and Analyzing Low-Permeability Fractured Gas Wells,” JPT (Feb. 1968) 193.

Pascal H., Quillian, R.G., Kingston, J.: "Analysis of Vertical Fracture Length and NonDarcy Flow Coefficient Using Variable Rate Tests," paper SPE 9438 presented at the 1980 SPE Annual Technical Conference and Exhibition, Dallas, Sept. 21-24

Rawlins,E.K. andSchellhardt, MA: “Back-Pressure Data on Natural Gas Wells and their Application to Production Practicess”,Monograph7, U.S. Bur, Mines (1936) 
RRC, I. (7/16/2006). To Initial 4-Point AOF Testing. Rail road commission of Texas Available: http://www.rrc.state.tx.us/index.html

SLB, I. Schlumberger Oilfield Glossary, Available: http://www.slb.com.

Solving cubic equation, http//www.1728.com/cubic2.htm

Tek, M.R., Coats, K.H., and Katz, D.L.: "The Effect of Turbulence on Flow of Natural Gas Through Porous Media,"JPT (July 1962) 799-806.

Thauvin, F., and Mohanty, K.K.: "Network Modeling of Non-Darcy Flow through Porous Media," Transport in Porous Media (1998) 31, 19-37.

Umnuayponwiwat, S., Ozkan, E., Pearson, C. and Vincent, M., "Effect of non-Darcy Flow on the Interpretation of Transient Pressure Responses of Hydraulically Fractured Wells,” SPE 63176, presented at the 2000 SPE Annual Technical Conference and Exhibition, Dallas, Texas, U.S.A, October 1-4, 2000.

Wattenbarger. R., Henry. J., and Ramey, J, "Well Test Interpretation of Vertically Fractured Gas Wells,” SPE 2155.

Wattenbarger, R. A. and Ramey, H. J., Jr.: "Gas Well Testing with Turbulence, Damage and Wellbore Storage", J. Pet. Tech. (August 1968) 877-887. 
Wattenbarger, R. A. and Ramey, Jr., H. J.: "Well Test Interpretation of Vertically Fractured Gas Wells,” JPT (May1969) 625.

Lee, W.J.: Well Testing, SPE Textbook Series, Richardson, TX (1982). 
APPE NDIXES 


\section{APPENDIX A}

\section{PSEUDO-PRESSURE CALCULATION}

\section{Steps for pseudo-pressure calculation:}

Pseudo-pressure is simply described by Eq.1. Pseudo-pressure can be computed using numerical integration. In order to determine the relationship among pressure and pseudopressure, the following steps was performed (See Eq.30-32) (Alvarez et al 2000).

$$
\begin{aligned}
& \frac{2 P}{\mu z} \\
& \frac{2 p}{z} \\
& \frac{\overline{2 p}}{z}
\end{aligned}
$$

\section{Dr. Aminian Program is written using the following equations:}

Initially, $\mathrm{Z}$ factor is calculated by performing the following series of calculations (See Equations 33-36) (Alvarez et al 2000).

$$
\begin{gathered}
\mathrm{P}_{\mathrm{pc}}=709.6-58.7 * \gamma_{\mathrm{g}} \\
\mathrm{T}_{\mathrm{pc}}=170.5+307.3 * \gamma \mathrm{g} \\
\mathrm{Tr}=\mathrm{T} / \mathrm{T}_{\mathrm{pc}} \\
\operatorname{Pr}=\mathrm{P} / \mathrm{P}_{\mathrm{pc}}
\end{gathered}
$$


The reduced density was calculated using Newton's method. This method also used to estimate the $\mathrm{z}$ factor with the procedure described by Dranchuk, Purvis and Robinson.

The ${ }_{k+1}$ estimation is determined from the $\mathrm{P}_{\mathrm{k}}$ estimate using the Equation 37

$$
p_{k} \quad p_{k} \frac{f\left(p_{k}\right)}{f\left(p_{k}\right)}
$$

\section{Where:}
$f(p) \quad a p^{6} \quad b p^{3} \quad c p^{2} \quad d p \quad e p^{3}\left(\begin{array}{lll}1 & f p^{2}\end{array}\right) \exp \left[\begin{array}{lll}f p^{2} & g\end{array}\right.$

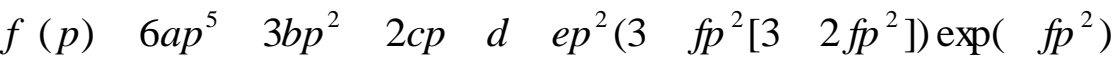

\section{Where:}

$$
\begin{aligned}
& \mathrm{a}=0.06423 \\
& \text { b } \quad 0.5353 T_{r} \quad 0.6123 \\
& c=0.3151 \mathrm{~T}_{\mathrm{r}} \quad 1.0467 \quad \frac{0.5783}{\mathrm{~T}_{\mathrm{r}}{ }^{2}} \\
& \mathrm{~d}=\mathrm{T}_{\mathrm{r}} \\
& \text { e } \frac{0.6816}{T_{r}{ }^{2}} \\
& f=0.6845 \\
& \mathrm{~g}=0.27 \mathrm{p}_{\mathrm{r}} \\
& p_{0} \quad 0.27 \frac{p_{r}}{T_{r}} \\
& z \quad \frac{0.27 p_{r}}{p T_{r}}
\end{aligned}
$$


The next step is the calculation of gas viscosity, g. This is done in two steps, first the Carr, Kobayashi and Burrows gas viscosity $\mathrm{g}_{1}$ was determined, and next the Dempsey method (1965) was used for final calculation:

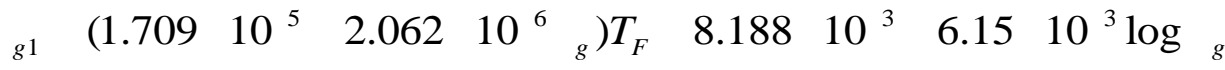

$$
\begin{aligned}
& \mathrm{yN}_{2}\left(8.48 \quad 10^{3} \log \text { g } 9.59 \quad 10^{3}\right) \\
& \mathrm{yCO}_{2}\left(9.08 \quad 10^{3} \log \text { g } 6.24 \quad 10^{3}\right) \\
& \mathrm{yH}_{2} \mathrm{~S}\left(8.4910^{3} \log \text { g } 3.73 \quad 10^{3}\right)
\end{aligned}
$$

$$
\begin{aligned}
& \ln T_{r} \frac{g}{g 1} \quad a_{0} \quad a_{1} p_{1} \quad a_{2} p_{r}{ }^{2} \quad a_{3} p_{r}{ }^{3} \quad T_{r}\left(\begin{array}{lllll}
a_{4} & a_{5} p_{r} & a_{6} p_{r}{ }^{2} & a_{7} p_{r}{ }^{7}
\end{array}\right) \\
& \mathrm{T}_{\mathrm{r}}{ }^{2}\left(\begin{array}{llllll}
a_{8} & a_{9} p_{r} & a_{10} p_{r}{ }^{2} & a_{11} p_{r}{ }^{2}
\end{array}\right) \quad T_{r}{ }^{3}\left(\begin{array}{lllll}
a_{12} & a_{13} p_{r} & a_{14} p_{r}{ }^{2} & a_{15} p_{r}{ }^{2}
\end{array}\right)
\end{aligned}
$$

Constant's values are listed below:

$$
\begin{aligned}
& a_{0}=-2.46211820 \\
& a_{1}=2.97054714 \\
& a_{2}=-2.86264054 \times 10^{-1} \\
& a_{3}=8.05420522 \times 10^{-3} \\
& a_{4}=2.80860949 \\
& a_{5}=-3.49803305 \\
& a_{6}=3.60373020 \times 10^{-1} \\
& a_{7}=-1.04432413 \times 10^{-2} \\
& a_{8}=-7.93385684 \times 10^{-1} \\
& a_{9}=1.39643306 \\
& a_{10}=-1.49144925 \times 10^{-1}
\end{aligned}
$$




$$
\begin{aligned}
& a_{11}=4.41015512 \times 10^{-3} \\
& a_{12}=8.39387176 \times 10^{-2} \\
& a_{13}=-1.86408848 \times 10^{-1} \\
& a_{14}=2.03367881 \times 10^{-2} \\
& a_{15}=-6.09579263 \times 10^{-4}
\end{aligned}
$$

Table A-1: Z factor, viscosity, and compressibility results

\begin{tabular}{|c|c|c|}
\hline P, psia & $\mathbf{z}$ & $\boldsymbol{\mu}, \mathbf{C p}$ \\
\hline 100 & 0.9888498 & $1.15 \mathrm{E}-02$ \\
\hline 200 & 0.9778506 & $1.16 \mathrm{E}-02$ \\
\hline 300 & 0.9670271 & $1.17 \mathrm{E}-02$ \\
\hline 400 & 0.9564064 & $1.19 \mathrm{E}-02$ \\
\hline 500 & 0.9460179 & $1.20 \mathrm{E}-02$ \\
\hline 600 & 0.9358935 & $1.22 \mathrm{E}-02$ \\
\hline 700 & 0.9260672 & $1.23 \mathrm{E}-02$ \\
\hline 800 & 0.9165752 & $1.25 \mathrm{E}-02$ \\
\hline 900 & 0.9074554 & $1.27 \mathrm{E}-02$ \\
\hline 1000 & 0.8987471 & $1.29 \mathrm{E}-02$ \\
\hline 1100 & 0.8904899 & $1.32 \mathrm{E}-02$ \\
\hline 1200 & 0.8827233 & $1.34 \mathrm{E}-02$ \\
\hline 1300 & 0.8754857 & 0.0136592 \\
\hline 1400 & 0.8688135 & $1.39 \mathrm{E}-02$ \\
\hline 1500 & 0.8627393 & $1.42 \mathrm{E}-02$ \\
\hline 1600 & 0.8572918 & $1.44 \mathrm{E}-02$ \\
\hline 1700 & 0.8524943 & 0.0147049 \\
\hline 1800 & 0.848364 & 0.0149649 \\
\hline 1900 & 0.8449116 & $1.52 \mathrm{E}-02$ \\
\hline 2000 & 0.8421413 & $1.55 \mathrm{E}-02$ \\
\hline 2100 & 0.8400503 & $1.58 \mathrm{E}-02$ \\
\hline 2200 & 0.83863 & $1.61 \mathrm{E}-02$ \\
\hline 2300 & 0.8378659 & 0.0164531 \\
\hline 2400 & 0.8377392 & $1.68 \mathrm{E}-02$ \\
\hline 2500 & 0.8382268 & $1.71 \mathrm{E}-02$ \\
\hline 2600 & 0.839303 & $1.74 \mathrm{E}-02$ \\
\hline 2700 & 0.8409398 & $1.78 \mathrm{E}-02$ \\
\hline & & \\
\hline
\end{tabular}




\begin{tabular}{|l|l|l|}
2800 & 0.8431082 & $1.81 \mathrm{E}-02$ \\
\hline 2900 & 0.8457785 & $1.85 \mathrm{E}-02$ \\
\hline 3000 & 0.8489212 & $1.88 \mathrm{E}-02$ \\
\hline
\end{tabular}

Table A-2: Pseudo-pressure calculation using the z factor, viscosity, compressibility values from stimulator

\begin{tabular}{|c|c|c|c|c|}
\hline $2 \mathrm{P} / \mu \mathrm{z}$ & $\mathrm{avg}(2 \mathrm{P} / \mu \mathrm{z})$ & $\mathrm{dP}$ & $\mathrm{avg}(2 \mathrm{P} / \mu \mathrm{z}) \mathrm{X} \mathrm{dP}$ & $\mathrm{m}(\mathrm{p}), \mathrm{psia} / \mathrm{cp}^{2}$ \\
\hline 12292.83149 & 6146.415745 & 100 & 614641.5745 & 614641.5745 \\
\hline 24376.28826 & 18334.55987 & 100 & 1833455.987 & 2448097.562 \\
\hline $3.63 \mathrm{E}+04$ & 30320.60355 & 100 & 3032060.355 & 5480157.917 \\
\hline 47970.58322 & 42117.75104 & 100 & 4211775.104 & 9691933.021 \\
\hline 59500.95612 & 53735.76967 & 100 & 5373576.967 & 15065509.99 \\
\hline 105175.9764 & 82338.46626 & 100 & 8233846.626 & 23299356.61 \\
\hline 123050.7353 & 114113.3558 & 100 & 11411335.58 & 34710692.2 \\
\hline 139592.4511 & 131321.5932 & 100 & 13132159.32 & 47842851.52 \\
\hline 156084.2471 & 147838.3491 & 100 & 14783834.91 & 62626686.42 \\
\hline 172167.9061 & 164126.0766 & 100 & 16412607.66 & 79039294.08 \\
\hline 187788.9995 & 179978.4528 & 100 & 17997845.28 & 97037139.36 \\
\hline 203015.5071 & 195402.2533 & 100 & 19540225.33 & 116577364.7 \\
\hline 217419.7676 & 210217.6373 & 100 & 21021763.73 & 137599128.4 \\
\hline 231440.1819 & 224429.9747 & 100 & 22442997.47 & 160042125.9 \\
\hline 245140.5117 & 238290.3468 & 100 & 23829034.68 & 183871160.6 \\
\hline 258408.3056 & 251774.4086 & 100 & 25177440.86 & 209048601.4 \\
\hline 271222.277 & 264815.2913 & 100 & 26481529.13 & 235530130.6 \\
\hline 283560.9682 & 277391.6226 & 100 & 27739162.26 & 263269292.8 \\
\hline 295405.2167 & 289483.0924 & 100 & 28948309.24 & 292217602.1 \\
\hline 306737.5189 & 301071.3678 & 100 & 30107136.78 & 322324738.8 \\
\hline 316493.8367 & 311615.6778 & 100 & 31161567.78 & 353486306.6 \\
\hline 325371.1615 & 320932.4991 & 100 & 32093249.91 & 385579556.5 \\
\hline 333684.1505 & 329527.656 & 100 & 32952765.6 & 418532322.1 \\
\hline 341438.5016 & 337561.3261 & 100 & 33756132.61 & 452288454.8 \\
\hline 348644.2979 & 345041.3998 & 100 & 34504139.98 & 486792594.7 \\
\hline 355313.7821 & 351979.04 & 100 & 35197904 & 521990498.7 \\
\hline 361453.2641 & 358383.5231 & 100 & 35838352.31 & 557828851 \\
\hline 366724.1437 & 364088.7039 & 100 & 36408870.39 & 594237721.4 \\
\hline 371515.2057 & 369119.6747 & 100 & 36911967.47 & 631149688.9 \\
\hline 375848.3187 & 373681.7622 & 100 & 37368176.22 & 668517865.1 \\
\hline
\end{tabular}




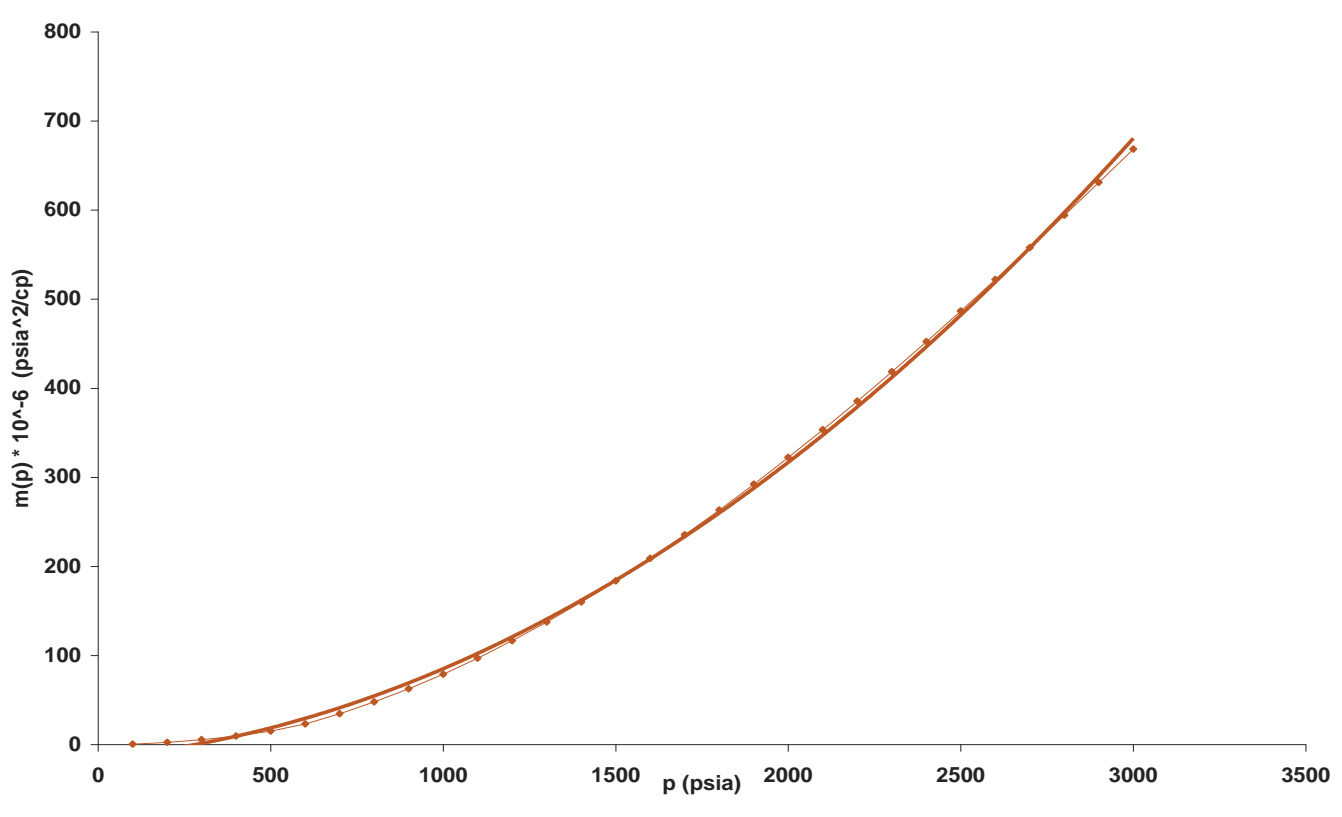

Figure A.1: Illustrates the nonlinearity of pseudo-pressure as a function of

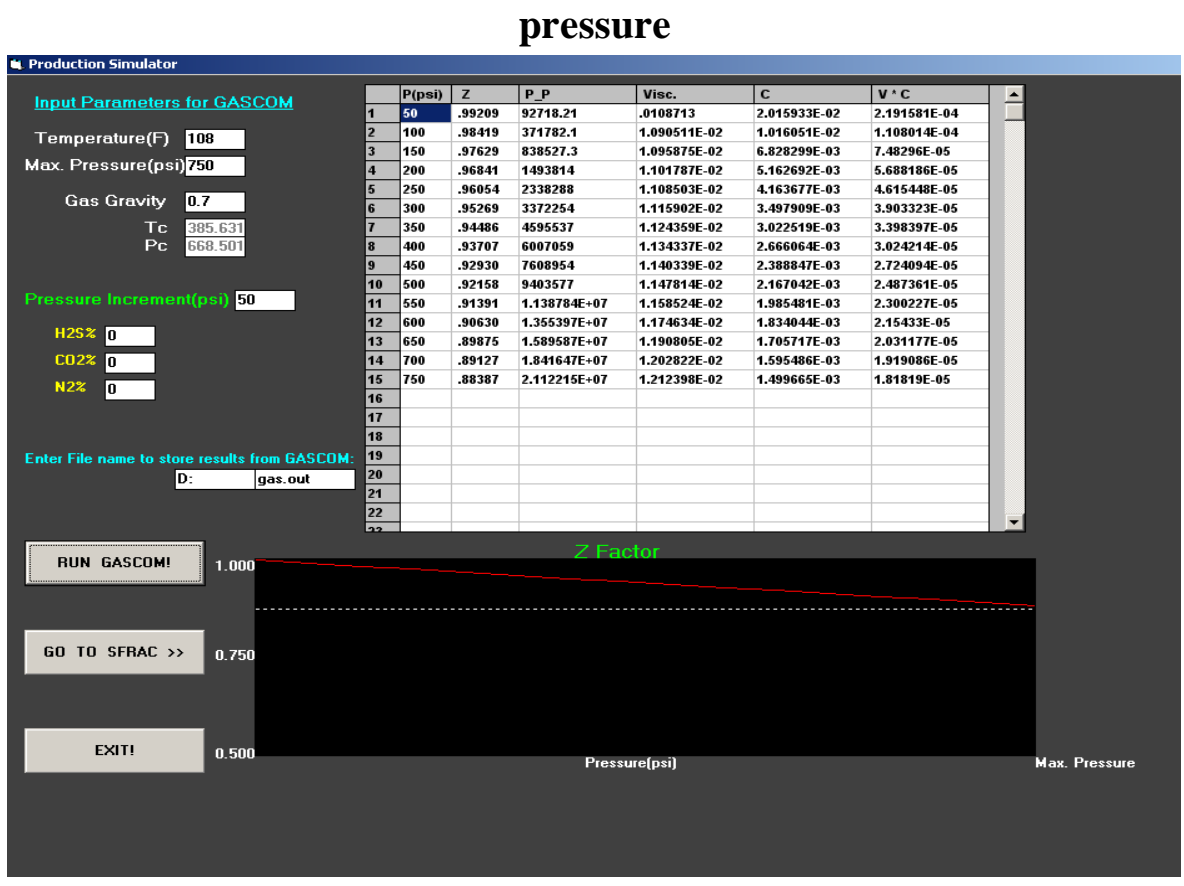

Figure A.2: $\mathbf{z}$ factor, viscosity, and compressibility calculation program (Aminian, 2000) 


\section{APPE NDIX B}

\section{AOFP DETERMINATION USING UNSTEADY STATE TRANSIENT RADIAL FLOW SOLUTION}

In order to find AOFP, unsteady state radial flow equation was used. Furthermore, Equation 4 was divided into three parts as follows:

$$
\begin{gathered}
\text { a } \frac{1637 T}{k h}[0.869 \mathrm{D}] \frac{1422 T \mathrm{D}}{\mathrm{kh}} \\
\text { b } \frac{1637 \mathrm{~T}}{\mathrm{kh}}\left[\log \mathrm{t} \log \frac{\mathrm{k}}{\mathrm{c}_{\mathrm{ti}} \mathrm{r}_{\mathrm{w}}^{2}} 3.23 \quad 0.869 \mathrm{~S}\right] \\
c \quad m\left(p_{\mathrm{i}}\right) \quad m\left(p_{\mathrm{wf}}\right)
\end{gathered}
$$

To calculate AOFP, quadratic formula in the excel program was used.

$$
x \frac{b \sqrt{b^{2} 4 a c}}{2 a}
$$


Table B-1 shows, the steps in calculation of AOFP for a skin factor of 3, using unsteady state transient radial flow equation.

\section{Table B-1:T he calculation steps for predicting AOF ( $P=1500 \mathrm{psi}, t=1 \mathrm{hr}$, and $\mathbf{S}=\mathbf{3}$ )}

\begin{tabular}{|c|c|c|c|c|c|}
\hline $\mathrm{K}(\mathrm{md})$ & $\mathrm{D},(\mathrm{MSCF} / \mathrm{D})^{-1}$ & $\mathrm{a}$ & $\mathrm{b}$ & $\mathrm{c}$ & $\begin{array}{c}\text { AOFP, } \\
\text { MSCF/D }\end{array}$ \\
\hline 0.1 & 0.00010523 & 8.080418 & 382148.2 & -183781637 & 476.1238 \\
\hline 0.2 & $9.16082 \mathrm{E}-05$ & 3.517206 & 204379.3 & -183781637 & 885.7177 \\
\hline 0.3 & $8.44727 \mathrm{E}-05$ & 2.162163 & 141441.6 & -183781637 & 1274.515 \\
\hline 0.4 & $7.97496 \mathrm{E}-05$ & 1.530953 & 108842.3 & -183781637 & 1650.209 \\
\hline 0.5 & $7.62687 \mathrm{E}-05$ & 1.171305 & 88787.16 & -183781637 & 2016.281 \\
\hline 0.6 & $7.35377 \mathrm{E}-05$ & 0.941136 & 75155.87 & -183781637 & 2374.722 \\
\hline 0.7 & $7.13051 \mathrm{E}-05$ & 0.782197 & 65264.74 & -183781637 & 2726.825 \\
\hline 0.8 & $6.94261 \mathrm{E}-05$ & 0.666386 & 57747.45 & -183781637 & 3073.499 \\
\hline 0.9 & $6.78097 \mathrm{E}-05$ & 0.578553 & 51833.48 & -183781637 & 3415.414 \\
\hline 1 & $6.63958 \mathrm{E}-05$ & 0.50984 & 47054.62 & -183781637 & 3753.089 \\
\hline
\end{tabular}

Table B-2: The calculation steps for predicting AOFP, using different $\beta$ correlation (J anecicek, $\mathrm{K}$ atz)

\begin{tabular}{|c|c|c|c|c|c|c|c|c|}
\hline $\mathrm{K}$, md & $\beta$ & $\mathrm{D}, \underset{1}{(\mathrm{MSCF} / \mathrm{D})^{-}}$ & $\mathrm{S}$ & $\mathrm{a}$ & $\mathrm{b}$ & $\mathrm{c}$ & AOF, MSCF/D & $\begin{array}{c}\log \\
\mathrm{k}+0.87 \mathrm{~S}\end{array}$ \\
\hline 0.1 & $3.30 \mathrm{E}+11$ & 9.39E-05 & -5 & 7.746223 & -278190.6 & -183781636.6 & 36561.97907 & -5.4 \\
\hline 0.2 & $1.39 \mathrm{E}+11$ & $7.90 \mathrm{E}-05$ & -4 & 3.256885 & -83550.50 & -183781636.6 & 27691.27333 & -4.2 \\
\hline 0.3 & $8.36 \mathrm{E}+10$ & $7.14 \mathrm{E}-05$ & -3 & 1.961952 & -22624.59 & -183781636.6 & 17031.61245 & -3.1 \\
\hline 0.4 & $5.83 \mathrm{E}+10$ & $6.64 \mathrm{E}-05$ & -2 & 1.369351 & 6624.182 & -183781636.6 & 9416.00505 & -2.1 \\
\hline 0.5 & $4.41 \mathrm{E}+10$ & $6.28 \mathrm{E}-05$ & -1 & 1.036042 & 23641.20 & -183781636.6 & 6128.068178 & -1.2 \\
\hline 0.6 & $3.51 \mathrm{E}+10$ & $6.00 \mathrm{E}-05$ & 0 & 0.824899 & 34705.33 & -183781636.6 & 4757.508747 & -0.2 \\
\hline 0.7 & $2.90 \mathrm{E}+10$ & $5.77 \mathrm{E}-05$ & 1 & 0.68032 & 42442.34 & -183781636.6 & 4065.242196 & 0.7 \\
\hline 0.8 & $2.45 \mathrm{E}+10$ & $5.58 \mathrm{E}-05$ & 2 & 0.575741 & 48138.82 & -183781636.6 & 3657.729329 & 1.6 \\
\hline 0.9 & $2.12 \mathrm{E}+10$ & $5.42 \mathrm{E}-05$ & 3 & 0.496920 & 52497.26 & -183781636.6 & 3391.88367 & 2.6 \\
\hline 1 & $1.86 \mathrm{E}+10$ & $5.28 \mathrm{E}-05$ & 4 & 0.435602 & 55932.79 & -183781636.6 & 3205.723733 & 3.5 \\
\hline
\end{tabular}


Figure B-1 illustrates the impact of skin on relationship between permeability and AOFP for $(\mathrm{P}=2000 \mathrm{psia}, \mathrm{t}=1 \mathrm{hr}$, and $\mathrm{S}=-3$ to 3$)$.

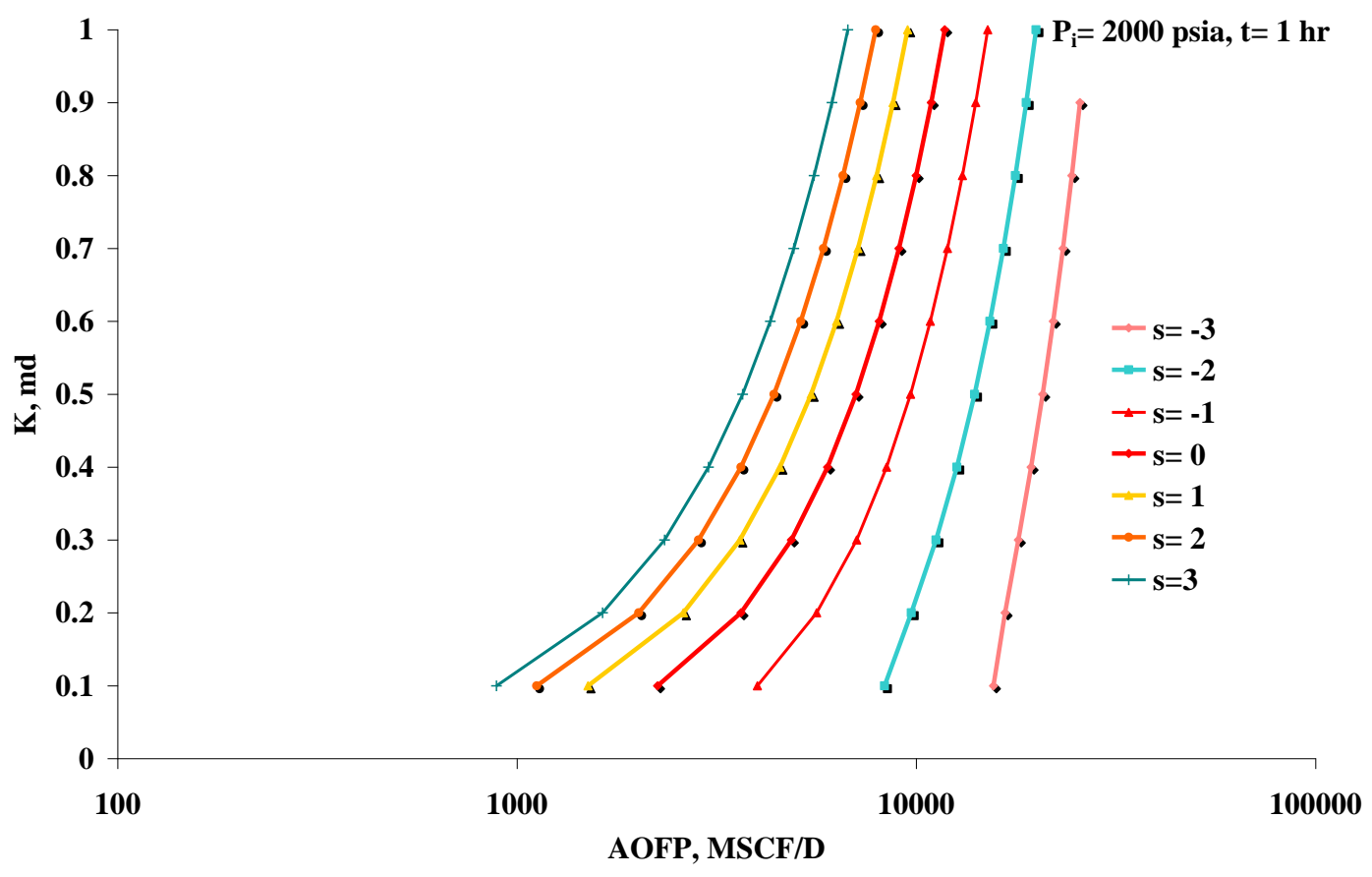

Figure B-1: Permeability vs. AOF P $(P=2000$ psia, $t=1 \mathrm{hr}$, and $S=-3$ to 3$)$ 


\title{
APPENDIX C \\ AOFP DETERMINATION USING PSEUDO-STEADY STATE RADIAL FLOW SOLUTION
}

In order to find AOFP, the quadratic formula was used. To find all parameters of the quadratic formula, equation 7 was divided into three parts as following:

\author{
a $\quad \mathrm{D} \quad \mathrm{C}_{1}$ \\ b $C_{1} \quad \ln \left(\frac{0.472 r_{e}}{r_{w}}\right) \quad S$ \\ c $m\left(\overline{p_{r}}\right) \quad m\left(\overline{p_{w f}}\right)$
}

\section{Where}

$\mathrm{C}_{1} \frac{1422 \mathrm{~T}}{\mathrm{kh}}$

The following table shows the tabulated results of AOFP for constant permeability $(\mathrm{k}=0.5)$ and skin factor ranges of -3 to 5.

Table C -1: Steps for estimation AOFP using pseudo-steady state equation

\begin{tabular}{|c|c|c|c|c|c|c|}
\hline D, $(M S C F / D)^{-1}$ & $\mathbf{S}$ & C1 & a & b & c & $\begin{array}{c}\text { AOF, } \\
\text { MSCF/D }\end{array}$ \\
\hline \multicolumn{7}{|l|}{0.000126467} \\
\hline 0.000126467 & -3.0 & 15357.6 & 1.942229389 & 59128.69761 & -183960684.6 & 2845.271965 \\
\hline 0.000126467 & -2.75 & 15357.6 & 1.942229389 & 62968.09761 & -183960684.6 & 2697.113279 \\
\hline 0.000126467 & -2.5 & 15357.6 & 1.942229389 & 66807.49761 & -183960684.6 & 2562.669417 \\
\hline 0.000126467 & -2.25 & 15357.6 & 1.942229389 & 70646.89761 & -183960684.6 & 2440.237097 \\
\hline 0.000126467 & -2.0 & 15357.6 & 1.942229389 & 74486.29761 & -183960684.6 & 2328.365239 \\
\hline 0.000126467 & -1.75 & 15357.6 & 1.942229389 & 78325.69761 & -183960684.6 & 2225.813589 \\
\hline
\end{tabular}




\begin{tabular}{|c|c|c|c|c|c|c|}
\hline 0.000126467 & -1.5 & 15357.6 & 1.942229389 & 82165.09761 & -183960684.6 & 2131.51839 \\
\hline 0.000126467 & -1.25 & 15357.6 & 1.942229389 & 86004.49761 & -183960684.6 & 2044.563959 \\
\hline 0.000126467 & -1 & 15357.6 & 1.942229389 & 89843.89761 & -183960684.6 & 1964.159182 \\
\hline 0.000126467 & -0.75 & 15357.6 & 1.942229389 & 93683.29761 & -183960684.6 & 1889.618057 \\
\hline 0.000126467 & -0.5 & 15357.6 & 1.942229389 & 97522.69761 & -183960684.6 & 1820.343563 \\
\hline 0.000126467 & 0 & 15357.6 & 1.942229389 & 105201.4976 & -183960684.6 & 1695.573167 \\
\hline 0.000126467 & 0.5 & 15357.6 & 1.942229389 & 112880.2976 & -183960684.6 & 1586.395294 \\
\hline 0.000126467 & 0.75 & 15357.6 & 1.942229389 & 116719.6976 & -183960684.6 & 1536.790095 \\
\hline 0.000126467 & 1.0 & 15357.6 & 1.942229389 & 120559.0976 & -183960684.6 & 1490.124147 \\
\hline 0.000126467 & 1.25 & 15357.6 & 1.942229389 & 124398.4976 & -183960684.6 & 1446.149355 \\
\hline 0.000126467 & 1.5 & 15357.6 & 1.942229389 & 128237.8976 & -183960684.6 & 1404.644183 \\
\hline 0.000126467 & 1.75 & 15357.6 & 1.942229389 & 132077.2976 & -183960684.6 & 1365.41027 \\
\hline 0.000126467 & 2.0 & 15357.6 & 1.942229389 & 135916.6976 & -183960684.6 & 1328.269539 \\
\hline 0.000126467 & 2.25 & 15357.6 & 1.942229389 & 139756.0976 & -183960684.6 & 1293.061722 \\
\hline 0.000126467 & 2.5 & 15357.6 & 1.942229389 & 143595.4976 & -183960684.6 & 1259.642225 \\
\hline 0.000126467 & 2.75 & 15357.6 & 1.942229389 & 147434.8976 & -183960684.6 & 1227.880289 \\
\hline 0.000126467 & 3.0 & 15357.6 & 1.942229389 & 151274.2976 & -183960684.6 & 1197.657408 \\
\hline 0.000126467 & 3.25 & 15357.6 & 1.942229389 & 155113.6976 & -183960684.6 & 1168.865942 \\
\hline 0.000126467 & 3.75 & 15357.6 & 1.942229389 & 162792.4976 & -183960684.6 & 1115.193997 \\
\hline 0.000126467 & 4.0 & 15357.6 & 1.942229389 & 166631.8976 & -183960684.6 & 1090.142529 \\
\hline 0.000126467 & 4.25 & 15357.6 & 1.942229389 & 170471.2976 & -183960684.6 & 1066.17878 \\
\hline 0.000126467 & 4.5 & 15357.6 & 1.942229389 & 174310.6976 & -183960684.6 & 1043.234212 \\
\hline 0.000126467 & 4.75 & 15357.6 & 1.942229389 & 178150.0976 & -183960684.6 & 1021.245861 \\
\hline 0.000126467 & 5 & 15357.6 & 1.942229389 & 181989.4976 & -183960684.6 & 1000.155791 \\
\hline
\end{tabular}




\section{APPENDIX D}

\section{AOFP DETERMINATION USING BILINEAR, LINEAR, RADIAL FLOW REGIME}

AOFP derivation steps based on analytical expression of bilinear flow regimes in finite conductivity fracture under Darcy flow conditions are defined as follows:

$$
\begin{gathered}
\frac{(5 / 4) \sqrt{2 C_{f D}}}{t_{D}^{1 / 4}} \frac{k h}{1,422 q T}\left[m\left(p_{i}\right) \quad m\left(p_{w f}\right)\right] \\
q \frac{k h\left[m\left(p_{i}\right)\right.}{\left.m\left(p_{w f}\right)\right]^{*}(5 / 4)\left(2 C_{f D}\right)^{\frac{1}{2}}} \\
\left(t_{D}^{1 / 4}\right)(1422 t)
\end{gathered}
$$

AOFP derivation steps based on analytical expression of bilinear flow regimes in finite conductivity fracture under non-Darcy flow conditions are defined as follows:

$$
\begin{aligned}
& \frac{}{(5 / 4) \sqrt{2 C_{f D, a p p}}} \mathrm{t}_{\mathrm{D}}^{1 / 4} \quad \frac{\mathrm{kh}}{1,422 \mathrm{qT}^{\mathrm{T}}}\left[\mathrm{m}\left(\mathrm{p}_{\mathrm{i}}\right) \quad \mathrm{m}\left(\mathrm{p}_{\mathrm{wf}}\right)\right] \\
& \frac{\mathrm{t}_{\mathrm{D}}^{\frac{1}{4}}}{\left(\frac{5}{4}\right)\left(\frac{2 \mathrm{C}_{\mathrm{fD}}}{1 \frac{0.31 * 4.64 * 10{ }^{16} \mathrm{k}_{\mathrm{f}} \mathrm{Mq}}{\mathrm{w}_{\mathrm{f}} \mathrm{h}_{\mathrm{i}}}}\right)^{\frac{1}{2}}} \frac{\mathrm{kh}\left[\mathrm{m}\left(\mathrm{p}_{\mathrm{i}}\right) \mathrm{m}\left(\mathrm{p}_{\mathrm{wf}}\right)\right]}{1422 \mathrm{qT}} \\
& {\left[\left(\frac{\operatorname{kh}\left\{m\left(p_{i}\right) m\left(p_{w f}\right)\right.}{1422 T q}\right)\left(\frac{2 C_{f D}}{1 \frac{0.31 * 4.64 * 10{ }^{16} k_{f} M q}{w_{f} h_{i}}}\right)^{\frac{1}{2}}\right]^{2} \quad\left[\frac{t_{D}^{\frac{1}{4}}}{\left(\frac{5}{4}\right)}\right]^{2}}
\end{aligned}
$$




$$
\begin{aligned}
& \frac{2 C_{f D}}{1 \frac{0.31 * 4.64 * 10{ }^{16} k_{f} M q}{w_{f} h_{i}}} * \frac{\left[k h\left\{m\left(p_{i}\right) m\left(p_{w f}\right)\right\}\right]^{2}}{(1422 q T)^{2}}\left(\frac{t_{D}^{\frac{1}{4}}}{\left(\frac{5}{4}\right)}\right)^{2} \\
& \frac{\left[k h\left\{m\left(p_{i}\right) \quad m\left(p_{w f}\right)\right\}\right]^{2}}{(1422 q T)^{2}} * \frac{2 C_{f D}}{\frac{w_{f} h_{i} \quad 0.31 * 4.64 * 10^{16} k_{f} M q}{w_{f} h_{i}}}\left(\frac{t_{D}^{\frac{1}{4}}}{\left(\frac{5}{4}\right)}\right)^{2} \\
& \frac{\left[k h\left\{m\left(p_{i}\right) \quad m\left(p_{w f}\right)\right\}\right]^{2} * 2 C_{f D}}{\frac{(1422 T)^{2} w_{f} h q^{2}(1422 T)^{2} * 0.31 * 4.64 * 10^{16} k_{f} M q^{3}}{w_{f} h}}\left(\frac{t_{D}^{\frac{1}{4}}}{5}\right)^{2} \\
& \frac{\left[\operatorname{kh}\left\{m\left(p_{i}\right) \quad m\left(p_{w f}\right)\right\}\right]^{2} * 2 C_{f D} * w_{f} h_{i}}{(1422 T)^{2} w_{f} h q^{2}(1422 T)^{2} * 0.31 * 4.64 * 10{ }^{16} k_{f} M q^{3}} \quad\left(\frac{t_{D}^{\frac{1}{4}}}{\left(\frac{5}{4}\right)}\right)^{2}
\end{aligned}
$$

\section{The procedure for AOFP calculation, for bilinear flow (non-D arcy) is as follows:}

The first step of the procedure was to break down the cubic equation 31, in to four parts as follow:

$$
\begin{gathered}
A=(1422 \mathrm{~T})^{2} * 0.31 * 4.64 * 1016 *\left(t_{d}^{\frac{1}{4}}\right)^{2} k_{f} B M q^{3} \\
B=(1422 T)^{2} w_{f} h_{i}\left(t_{d}^{\frac{1}{4}}\right)^{2} q^{2} \\
C=0 \\
D=[]^{2}\left[k h\left(m\left(p_{i}\right) \quad m\left(p_{w f}\right)\right]^{2}\left(2 C_{f d}\right) w_{f} h_{i}\right.
\end{gathered}
$$


Cubic equations have to be solved in several steps. First we define a variable ' $f$ ' (see equation 40):

Next $g$ value was defined:

$$
\mathrm{f} \frac{\frac{3 c}{a} \frac{b^{2}}{a^{2}}}{3}
$$

$$
g \frac{\frac{2 b^{3}}{a^{3}} \quad \frac{9 b c}{a^{2}} \frac{27 d}{a}}{27}
$$

Then "h" value was found:

$$
\text { h } \quad\left(\frac{g^{2}}{4}\right) \quad\left(\frac{f^{3}}{27}\right)
$$

For the special case where $\mathrm{f}=0, \mathrm{~g}=0$, and $\mathrm{h}=0$, all 3 roots are real and equal.

When $\mathrm{h}<=0$, as is the case here, all 3 roots are real and is solved by another method.

When only 1 root is real $(h>0)$, the $R, S, T$, and $U$ values are defined by following equation (see equation 43-12):

$$
\begin{aligned}
& R \quad\left(\frac{g}{2}\right) \quad\left(\frac{f^{3}}{27}\right) \\
& S(R)^{1 / 3} \\
& \mathrm{~T} \quad\left(\frac{g}{2}\right) \quad(h)^{1 / 2} \\
& U(T)^{1 / 3} \\
& X 1 \quad(S \quad U) \quad\left(\frac{b}{3 a}\right) \\
& X 2 \frac{(\mathrm{S} U)}{2} \frac{\mathrm{b}}{3 \mathrm{a}} \frac{\mathrm{i}(\mathrm{S} \cup) 3^{1 / 2}}{2} \\
& \text { X3 } \frac{(\mathrm{S} U)}{2} \frac{\mathrm{b}}{3 \mathrm{a}} \frac{\mathrm{i}(\mathrm{S} U) 3^{1 / 2}}{2}
\end{aligned}
$$


AOFP derivation steps based on analytical expression of linear flow regimes in finite conductivity fracture under Darcy flow conditions are defined as follows:

$$
\begin{aligned}
& \frac{k h}{1,422 q T}\left[m\left(p_{i}\right) \quad m\left(p_{w f}\right)\right] \quad \sqrt{t_{D}} \frac{a}{C_{f D}} \\
& \frac{\sqrt{t_{D}}}{1} \frac{a}{C_{f D}} \frac{k h}{1,422 q T}\left[m\left(p_{i}\right) \quad m\left(p_{w f}\right)\right] \\
& \frac{a \quad C_{f D} \sqrt{t_{D}}}{C_{f D}} \frac{k h}{1,422 q T}\left[m\left(p_{i}\right) \quad m\left(p_{W f}\right)\right] \\
& 1,422 q T C_{f D} \sqrt{t_{D}} \quad 1,422 q T a \quad C_{f D} k h\left[m\left(p_{i}\right) \quad m\left(p_{w f}\right)\right] \\
& q *\left[1,422 T C_{f D} \sqrt{t_{D}} \quad 1,422 T a\right] \quad C_{f D} k h\left[m\left(p_{i}\right) \quad m\left(p_{w f}\right)\right]
\end{aligned}
$$

AOFP derivation steps based on analytical expression of linear flow regimes in finite conductivity fracture under non-Darcy flow conditions are defined as follows:

$$
\begin{aligned}
& \frac{k h}{1,422 q T}\left[m\left(p_{i}\right)\right.\left.m\left(p_{w f}\right)\right] \sqrt{t_{D}} \frac{a}{C_{f D, a p p}} \\
& \frac{k h}{1,422 q T}\left[m\left(p_{i}\right) \quad m\left(p_{w f}\right)\right] \sqrt{t_{D}} \frac{\frac{a}{C_{f D}}}{\left(1 \frac{0.314 .64 \quad 10{ }^{16} k_{f} M q}{w_{f} h}\right)}
\end{aligned}
$$




$$
\sqrt{t_{D}} \frac{k h}{1,422 q T}\left[m\left(p_{i}\right) m\left(p_{w f}\right)\right] \frac{a}{\left.\frac{C_{f D}}{w_{1} \frac{0.31 \quad 4.64 \quad 10{ }^{16} k_{f}}{M q}}\right)}
$$

Next, make the left side of the equation the same denominator.

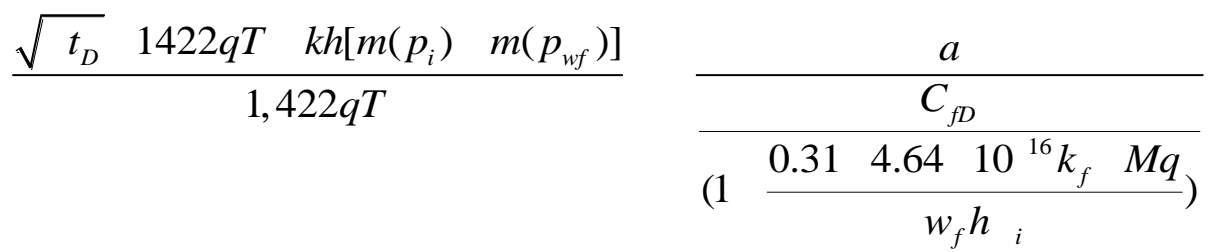

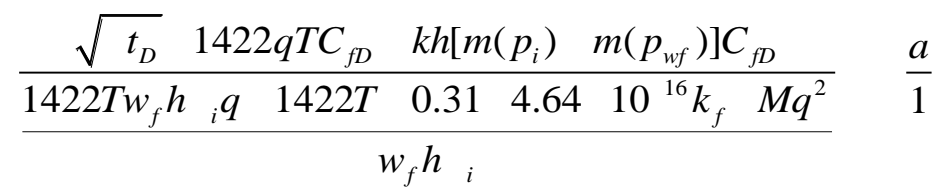

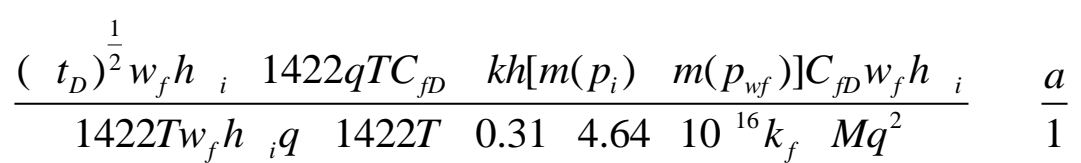

To attain the AOFP, the quadratic formula was used. To find all parameter for the quadratic formula, equation 32 was divided in to three parts. The following equations were used:

$$
\begin{aligned}
& \text { a } \quad\left[1422 \mathrm{~T} * 0.31 * 4.64 * 10{ }^{16} \mathrm{~K}_{\mathrm{f}} \quad\right. \text { M a '] } \\
& b \quad\left[1422 T_{a w} h ; 1422 T\left(t_{D}\right)^{\frac{1}{2}} C_{f D} w_{f} h_{i}\right] \\
& \text { C } \operatorname{kh}\left[m\left(p_{i}\right) \quad m\left(p_{w f}\right)\right] C_{f D} w_{f} h \text { i }
\end{aligned}
$$

By substituting all the formula in to the quadratic equation, the AOFP was found. 
Table D-1 and D-2 shows the results for steps of AOFP calculation using bilinear and linear Non-Darcy flow regime for $\mathrm{c}_{\mathrm{fd}}$ ranges (10-100).

Table D-1: AOF P calculation using bilinear non-Darcy flow regime $(p=1500$ psia and $K=0.5$ )

\begin{tabular}{|c|c|c|c|c|c|c|c|c|}
\hline $\mathrm{C}_{\mathrm{fD}}$ & $\mathrm{h}$ & $\mathrm{g}$ & $\mathrm{d}$ & $\mathrm{R}$ & $\mathrm{S}$ & $\mathrm{T}$ & $\mathrm{U}$ & $\begin{array}{c}\text { AOFP, } \\
\text { MSCF/D }\end{array}$ \\
\hline $1.00 \mathrm{E}+01$ & $1.39 E+25$ & $-7.46 \mathrm{E}+12$ & $-7.87 \mathrm{E}+19$ & $7.46 \mathrm{E}+12$ & $1.95 \mathrm{E}+04$ & 0 & 0 & $1.95 \mathrm{E}+04$ \\
\hline $2.00 \mathrm{E}+01$ & $5.57 \mathrm{E}+25$ & $-1.49 \mathrm{E}+13$ & $-1.57 \mathrm{E}+20$ & $1.49 \mathrm{E}+13$ & $2.46 \mathrm{E}+04$ & 0 & 0 & $2.46 \mathrm{E}+04$ \\
\hline $3.00 \mathrm{E}+01$ & $1.25 \mathrm{E}+26$ & $-2.24 \mathrm{E}+13$ & $-2.36 \mathrm{E}+20$ & $2.24 \mathrm{E}+13$ & $2.82 \mathrm{E}+04$ & 0 & 0 & $2.81 \mathrm{E}+04$ \\
\hline $4.00 \mathrm{E}+01$ & $2.23 \mathrm{E}+26$ & $-2.99 \mathrm{E}+13$ & $-3.15 \mathrm{E}+20$ & $2.99 \mathrm{E}+13$ & $3.10 \mathrm{E}+04$ & 0 & 0 & $3.10 \mathrm{E}+04$ \\
\hline $5.00 \mathrm{E}+01$ & $3.48 \mathrm{E}+26$ & $-3.73 E+13$ & $-3.94 \mathrm{E}+20$ & $3.73 E+13$ & $3.34 \mathrm{E}+04$ & 0 & 0 & $3.34 \mathrm{E}+04$ \\
\hline $6.00 \mathrm{E}+01$ & $5.01 \mathrm{E}+26$ & $-4.48 \mathrm{E}+13$ & $-4.72 E+20$ & $4.48 \mathrm{E}+13$ & $3.55 \mathrm{E}+04$ & 0 & & $3.55 \mathrm{E}+04$ \\
\hline $7.00 \mathrm{E}+01$ & $6.82 \mathrm{E}+26$ & $-5.22 \mathrm{E}+13$ & $-5.51 E+20$ & $5.22 \mathrm{E}+13$ & $3.74 \mathrm{E}+04$ & 0 & 0 & $3.73 \mathrm{E}+04$ \\
\hline $8.00 \mathrm{E}+01$ & $8.91 \mathrm{E}+26$ & $-5.97 \mathrm{E}+13$ & $-6.30 \mathrm{E}+20$ & $5.97 \mathrm{E}+13$ & $3.91 \mathrm{E}+04$ & 0 & 0 & $3.90 \mathrm{E}+04$ \\
\hline $9.00 \mathrm{E}+01$ & $1.13 \mathrm{E}+27$ & $-6.72 E+13$ & $-7.09 \mathrm{E}+20$ & $6.72 \mathrm{E}+13$ & $4.07 \mathrm{E}+04$ & 0 & 0 & $4.06 \mathrm{E}+04$ \\
\hline $1.00 \mathrm{E}+02$ & $1.39 \mathrm{E}+27$ & $-7.46 \mathrm{E}+13$ & $-7.87 \mathrm{E}+20$ & $7.46 \mathrm{E}+13$ & $4.21 \mathrm{E}+04$ & 0 & 0 & $4.21 \mathrm{E}+04$ \\
\hline
\end{tabular}

Table D-2: AOF P calculation using linear non-Darcy flow regime ( $p=1500$ psia and $K=0.5$ )

\begin{tabular}{|c|c|c|c|c|c|c|}
\hline $\mathrm{C}_{\mathrm{fD}}$ & $\mathrm{a}$ & $\mathrm{b}$ & $\mathrm{b}$ & $\mathrm{b}$ & $\mathrm{c}$ & AOFP,MSCF/D \\
\hline 10 & $1.04 \mathrm{E}+01$ & 257058.49 & $3.65 \mathrm{E}+04$ & $2.94 \mathrm{E}+05$ & $-3.26 \mathrm{E}+10$ & $4.37 \mathrm{E}+04$ \\
\hline 20 & $1.04 \mathrm{E}+01$ & 257058.49 & $7.29 \mathrm{E}+04$ & $3.30 \mathrm{E}+05$ & $-6.52 \mathrm{E}+10$ & $6.50 \mathrm{E}+04$ \\
\hline 30 & $1.15 \mathrm{E}+01$ & 285923.10 & $1.09 \mathrm{E}+05$ & $3.95 \mathrm{E}+05$ & $-9.78 \mathrm{E}+10$ & $7.65 \mathrm{E}+04$ \\
\hline 40 & $1.15 \mathrm{E}+01$ & 285923.10 & $1.46 \mathrm{E}+05$ & $4.32 \mathrm{E}+05$ & $-1.30 \mathrm{E}+11$ & $8.93 \mathrm{E}+04$ \\
\hline 50 & $1.15 \mathrm{E}+01$ & 285923.10 & $1.82 \mathrm{E}+05$ & $4.68 \mathrm{E}+05$ & $-1.63 \mathrm{E}+11$ & $1.00 \mathrm{E}+05$ \\
\hline 60 & $1.15 \mathrm{E}+01$ & 285923.10 & $2.19 \mathrm{E}+05$ & $5.05 \mathrm{E}+05$ & $-1.96 \mathrm{E}+11$ & $1.10 \mathrm{E}+05$ \\
\hline 70 & $1.15 \mathrm{E}+01$ & 285923.10 & $2.55 \mathrm{E}+05$ & $5.41 \mathrm{E}+05$ & $-2.28 \mathrm{E}+11$ & $1.19 \mathrm{E}+05$ \\
\hline 80 & $1.15 \mathrm{E}+01$ & 285923.10 & $2.92 \mathrm{E}+05$ & $5.78 \mathrm{E}+05$ & $-2.61 \mathrm{E}+11$ & $1.27 \mathrm{E}+05$ \\
\hline 90 & $1.15 \mathrm{E}+01$ & 285923.10 & $3.28 \mathrm{E}+05$ & $6.14 \mathrm{E}+05$ & $-2.93 \mathrm{E}+11$ & $1.35 \mathrm{E}+05$ \\
\hline 100 & $1.15 \mathrm{E}+01$ & 285923.10 & $3.65 \mathrm{E}+05$ & $6.50 \mathrm{E}+05$ & $-3.26 \mathrm{E}+11$ & $1.42 \mathrm{E}+05$ \\
\hline
\end{tabular}

Table D-3 and D-4 shows the results for steps of AOFP calculation using bilinear Non-

Darcy and Darcy flow regime for $\mathrm{C}_{\mathrm{fd}}$ ranges (10-100). 
Table D-3: Converting $C_{f d}$ values to skin factor and AOF P calculation using bilinear non-D arcy flow regime, ( $p=1500$ psia and $K=0.5, t=1 \mathrm{hr}$ )*

\begin{tabular}{|c|c|c|c|c|c|c|}
\hline $\mathrm{C}_{\mathrm{fD}}$ & $\mathrm{S}$ & $\mathrm{Xf}, \mathrm{ft}$ & $\mathrm{t}_{\mathrm{D}}$ & $\mathrm{a}$ & $\mathrm{b}$ & $\mathrm{c}$ \\
\hline 10 & -4.892852 & $1.00 \mathrm{E}+02$ & $6.34 \mathrm{E}-04$ & $4.91 \mathrm{E}+06$ & $2.08 \mathrm{E}+09$ & 0 \\
\hline $\mathbf{2 0}$ & $\mathbf{- 4 . 2 4 4 1 5 7}$ & $\mathbf{5 . 0 0 E}+\mathbf{0 1}$ & $\mathbf{2 . 5 4 E}-\mathbf{0 3}$ & $\mathbf{9 . 8 3 E}+06$ & $\mathbf{4 . 1 5 E}+09$ & \\
\hline 30 & -3.860198 & $3.33 \mathrm{E}+01$ & $5.71 \mathrm{E}-03$ & $1.47 \mathrm{E}+07$ & $6.23 \mathrm{E}+09$ & \\
\hline 40 & -3.593569 & $2.50 \mathrm{E}+01$ & $1.01 \mathrm{E}-02$ & $1.97 \mathrm{E}+07$ & $8.31 \mathrm{E}+09$ & \\
\hline 50 & -3.380789 & $2.00 \mathrm{E}+01$ & $1.59 \mathrm{E}-02$ & $2.46 \mathrm{E}+07$ & $1.04 \mathrm{E}+10$ & \\
\hline 60 & -3.208723 & $1.67 \mathrm{E}+01$ & $2.28 \mathrm{E}-02$ & $2.95 \mathrm{E}+07$ & $1.25 \mathrm{E}+10$ & \\
\hline 70 & -3.064725 & $1.43 \mathrm{E}+01$ & $3.11 \mathrm{E}-02$ & $3.44 \mathrm{E}+07$ & $1.45 \mathrm{E}+10$ & \\
\hline 80 & -2.933212 & $1.25 \mathrm{E}+01$ & $4.06 \mathrm{E}-02$ & $3.93 \mathrm{E}+07$ & $1.66 \mathrm{E}+10$ & \\
\hline 90 & -2.821459 & $1.11 \mathrm{E}+01$ & $5.14 \mathrm{E}-02$ & $4.42 \mathrm{E}+07$ & $1.87 \mathrm{E}+10$ & \\
\hline 100 & -2.718101 & $1.00 \mathrm{E}+01$ & $6.34 \mathrm{E}-02$ & $4.91 \mathrm{E}+07$ & $2.08 \mathrm{E}+10$ & \\
\hline
\end{tabular}

\begin{tabular}{|c|c|c|c|c|c|c|}
\hline $\mathrm{d}$ & $\mathrm{f}$ & $\mathrm{h}$ & $\mathrm{g}$ & $\mathrm{d}$ & $\mathrm{R}$ & $\mathrm{S}$ \\
\hline $0.00 \mathrm{E}+00$ & $-5.95 \mathrm{E}+04$ & $4.01 \mathrm{E}+24$ & $-4.01 \mathrm{E}+12$ & $-1.97 \mathrm{E}+19$ & $4.01 \mathrm{E}+12$ & $1.59 \mathrm{E}+04$ \\
\hline $0.00 \mathrm{E}+00$ & $-5.95 \mathrm{E}+04$ & $4.01 \mathrm{E}+24$ & $-4.01 \mathrm{E}+12$ & $-3.94 \mathrm{E}+19$ & $4.01 \mathrm{E}+12$ & $1.59 \mathrm{E}+04$ \\
\hline $0.00 \mathrm{E}+00$ & $-5.95 \mathrm{E}+04$ & $4.01 \mathrm{E}+24$ & $-4.01 \mathrm{E}+12$ & $-5.90 \mathrm{E}+19$ & $4.01 \mathrm{E}+12$ & $1.59 \mathrm{E}+04$ \\
\hline $0.00 \mathrm{E}+00$ & $-5.95 \mathrm{E}+04$ & $4.01 \mathrm{E}+24$ & $-4.01 \mathrm{E}+12$ & $-7.87 \mathrm{E}+19$ & $4.01 \mathrm{E}+12$ & $1.59 \mathrm{E}+04$ \\
\hline $0.00 \mathrm{E}+00$ & $-5.95 \mathrm{E}+04$ & $4.01 \mathrm{E}+24$ & $-4.01 \mathrm{E}+12$ & $-9.84 \mathrm{E}+19$ & $4.01 \mathrm{E}+12$ & $1.59 \mathrm{E}+04$ \\
\hline $0.00 \mathrm{E}+00$ & $-5.95 \mathrm{E}+04$ & $4.01 \mathrm{E}+24$ & $-4.01 \mathrm{E}+12$ & $-1.18 \mathrm{E}+20$ & $4.01 \mathrm{E}+12$ & $1.59 \mathrm{E}+04$ \\
\hline $0.00 \mathrm{E}+00$ & $-5.95 \mathrm{E}+04$ & $4.01 \mathrm{E}+24$ & $-4.01 \mathrm{E}+12$ & $-1.38 \mathrm{E}+20$ & $4.01 \mathrm{E}+12$ & $1.59 \mathrm{E}+04$ \\
\hline $0.00 \mathrm{E}+00$ & $-5.95 \mathrm{E}+04$ & $4.01 \mathrm{E}+24$ & $-4.01 \mathrm{E}+12$ & $-1.57 \mathrm{E}+20$ & $4.01 \mathrm{E}+12$ & $1.59 \mathrm{E}+04$ \\
\hline $0.00 \mathrm{E}+00$ & $-5.95 \mathrm{E}+04$ & $4.01 \mathrm{E}+24$ & $-4.01 \mathrm{E}+12$ & $-1.77 \mathrm{E}+20$ & $4.01 \mathrm{E}+12$ & $1.59 \mathrm{E}+04$ \\
\hline $0.00 \mathrm{E}+00$ & $-5.95 \mathrm{E}+04$ & $4.01 \mathrm{E}+24$ & $-4.01 \mathrm{E}+12$ & $-1.97 \mathrm{E}+20$ & $4.01 \mathrm{E}+12$ & $1.59 \mathrm{E}+04$ \\
\hline
\end{tabular}

\begin{tabular}{|c|c|c|}
\hline $\mathrm{T}$ & $\mathrm{U}$ & AOF, MSCF \\
\hline 1.950928 & 1.249253 & $1.57 \mathrm{E}+04$ \\
\hline 1.950928 & 1.249253 & $1.57 \mathrm{E}+04$ \\
\hline 1.950928 & 1.249253 & $1.57 \mathrm{E}+04$ \\
\hline 1.950928 & 1.249253 & $1.57 \mathrm{E}+04$ \\
\hline 1.950928 & 1.249253 & $1.57 \mathrm{E}+04$ \\
\hline 1.950928 & 1.249253 & $1.57 \mathrm{E}+04$ \\
\hline 1.950928 & 1.249253 & $1.57 \mathrm{E}+04$ \\
\hline 1.950928 & 1.249253 & $1.57 \mathrm{E}+04$ \\
\hline 1.950928 & 1.249253 & $1.57 \mathrm{E}+04$ \\
\hline 1.950928 & 1.249253 & $1.57 \mathrm{E}+04$ \\
\hline
\end{tabular}


Table D-4: C onverting $C_{\mathrm{fd}}$ values to skin factor and AOF P calculation using bilinear $D$ arcy flow regime $(p=1500$ psia and $K=0.5, t=1 \mathrm{hr}$ )*

\begin{tabular}{|c|c|c|c|c|c|}
\hline $\mathrm{C}_{\mathrm{fD}}$ & data for skin & $\mathrm{S}$ & $\mathrm{X}_{\mathrm{f}}, \mathrm{ft}$ & $\mathrm{t}_{\mathrm{D}}$ & AOFP, MSCF/D \\
\hline 10.00 & 2.27 & -4.89 & 100.00 & 0.00 & 97354.07 \\
\hline $\mathbf{2 0 . 0 0}$ & $\mathbf{2 . 1 7}$ & $\mathbf{- 4 . 2 4}$ & $\mathbf{5 0 . 0 0}$ & $\mathbf{0 . 0 0}$ & $\mathbf{9 7 3 5 4 . 0 7}$ \\
\hline 30.00 & 2.13 & -3.86 & 33.33 & 0.01 & 97354.07 \\
\hline 40.00 & 2.08 & -3.59 & 25.00 & 0.01 & 97354.07 \\
\hline 50.00 & 2.06 & -3.38 & 20.00 & 0.02 & 97354.07 \\
\hline 60.00 & 2.04 & -3.21 & 16.67 & 0.02 & 97354.07 \\
\hline 70.00 & 2.02 & -3.06 & 14.29 & 0.03 & 97354.07 \\
\hline 80.00 & 2.02 & -2.93 & 12.50 & 0.04 & 97354.07 \\
\hline 90.00 & 2.00 & -2.82 & 11.11 & 0.05 & 97354.07 \\
\hline 100.00 & 2.00 & -2.72 & 10.00 & 0.06 & 97354.07 \\
\hline
\end{tabular}

Table D-5 shows the results for steps of AOFP calculation using transient equation and adjusted skin factor* ( $\mathrm{p}=1500 \mathrm{psia}, \mathrm{K}=0.5 \mathrm{md}, \mathrm{S}=-4.24)$

Table D-5: AOF calculation using pressure transient equation for radial flow regime, $(p=1500 p s i a \text { and } K=0.5)^{*}$

\begin{tabular}{|c|c|c|c|c|c|c|}
\hline & & & & & & \\
t(hrs) & $\mathbf{D}$ & $\mathbf{S}$ & $\mathbf{a}$ & $\mathbf{b}$ & $\mathbf{C}$ & $\begin{array}{c}\text { AOF P, } \\
\text { M SCF/D }\end{array}$ \\
\hline 0 & 0.000108186 & & & & & \\
\hline 0.09 & 0.000108186 & -4.24415684 & 1.661484987 & -46319.636 & -183781636.6 & 31401.04241 \\
\hline 0.19 & 0.000108186 & -4.24415684 & 1.661484987 & -40582.41 & -183781636.6 & 28329.84893 \\
\hline 0.29 & 0.000108186 & -4.24415684 & 1.661484987 & -37335.651 & -183781636.6 & 26625.62976 \\
\hline 0.39 & 0.000108186 & -4.24415684 & 1.661484987 & -35060.877 & -183781636.6 & 25448.64592 \\
\hline 0.49 & 0.000108186 & -4.24415684 & 1.661484987 & -33308.272 & -183781636.6 & 24552.45578 \\
\hline 1 & 0.000108186 & -4.24415684 & 1.661484987 & -27831.062 & -183781636.6 & 21820.04056 \\
\hline 2 & 0.000108186 & -4.24415684 & 1.661484987 & -22508.972 & -183781636.6 & 19283.61093 \\
\hline 4 & 0.000108186 & -4.24415684 & 1.661484987 & -17186.883 & -183781636.6 & 16892.38228 \\
\hline 4.99 & 0.000108186 & -4.24415684 & 1.661484987 & -15488.924 & -183781636.6 & 16165.05391 \\
\hline 5.99 & 0.000108186 & -4.24415684 & 1.661484987 & -14086.467 & -183781636.6 & 15578.56459 \\
\hline 6.99 & 0.000108186 & -4.24415684 & 1.661484987 & -12901.044 & -183781636.6 & 15093.35039 \\
\hline 9.99 & 0.000108186 & -4.24415684 & 1.661484987 & -10159.144 & -183781636.6 & 14009.85738 \\
\hline 11.99 & 0.000108186 & -4.24415684 & 1.661484987 & -8757.9707 & -183781636.6 & 13478.05676 \\
\hline 13.99 & 0.000108186 & -4.24415684 & 1.661484987 & -7573.4635 & -183781636.6 & 13040.50434 \\
\hline 15.99 & 0.000108186 & -4.24415684 & 1.661484987 & -6547.503 & -183781636.6 & 12670.62277 \\
\hline 17.99 & 0.000108186 & -4.24415684 & 1.661484987 & -5642.6134 & -183781636.6 & 12351.5274 \\
\hline
\end{tabular}




\begin{tabular}{|l|l|l|l|l|l|l|}
\hline 19.99 & 0.000108186 & -4.24415684 & 1.661484987 & -4833.2125 & -183781636.6 & 12071.84922 \\
\hline 21.99 & 0.000108186 & -4.24415684 & 1.661484987 & -4101.0572 & -183781636.6 & 11823.58353 \\
\hline 23.99 & 0.000108186 & -4.24415684 & 1.661484987 & -3432.6796 & -183781636.6 & 11600.89134 \\
\hline 25.99 & 0.000108186 & -4.24415684 & 1.661484987 & -2817.8532 & -183781636.6 & 11399.38895 \\
\hline 27.99 & 0.000108186 & -4.24415684 & 1.661484987 & -2248.6299 & -183781636.6 & 11215.70564 \\
\hline 29.99 & 0.000108186 & -4.24415684 & 1.661484987 & -1718.7092 & -183781636.6 & 11047.19686 \\
\hline 31.99 & 0.000108186 & -4.24415684 & 1.661484987 & -1223.0126 & -183781636.6 & 10891.75165 \\
\hline 33.99 & 0.000108186 & -4.24415684 & 1.661484987 & -757.38629 & -183781636.6 & 10747.65967 \\
\hline 35.99 & 0.000108186 & -4.24415684 & 1.661484987 & -318.38976 & -183781636.6 & 10613.51698 \\
\hline 37.99 & 0.000108186 & -4.24415684 & 1.661484987 & 96.858906 & -183781636.6 & 10488.15782 \\
\hline 47.99 & 0.000108186 & -4.24415684 & 1.661484987 & 1891.0105 & -183781636.6 & 9963.577879 \\
\hline 48.99 & 0.000108186 & -4.24415684 & 1.661484987 & 2049.3611 & -183781636.6 & 9918.606657 \\
\hline 49.99 & 0.000108186 & -4.24415684 & 1.661484987 & 2204.512 & -183781636.6 & 9874.75253 \\
\hline
\end{tabular}

*Note: Adjusted skin factor was bolded for table D-3, D-4, and D-5 